$\begin{array}{ll}\text { Italique } & \text { Italique } \\ \text { Poésie italienne de la Renaissance }\end{array}$

$\mathrm{XV} \mid 2012$

Varia

\title{
«Le ali del pensiero»: échos, résonances et intertextes pétrarquistes dans L'Olive de Du Bellay
}

\section{Rosanna Gorris Camos}

\section{(2) OpenEdition}

Journals

\section{Édition électronique}

URL : http://journals.openedition.org/italique/346

DOI : 10.4000/italique.346

ISSN : 1663-4438

Éditeur

Librairie Droz

\section{Édition imprimée}

Date de publication : 1 décembre 2012

Pagination : 73-136

ISBN : 978-2-600-01639-1

ISSN : 1423-3983

Référence électronique

Rosanna Gorris Camos, « «Le ali del pensiero»: échos, résonances et intertextes pétrarquistes dans L'Olive de Du Bellay », Italique [En ligne], XV | 2012, mis en ligne le 01 décembre 2015, consulté le 19 avril 2019. URL : http://journals.openedition.org/italique/346 ; DOI : 10.4000/italique.346

(C) Tous droits réservés 


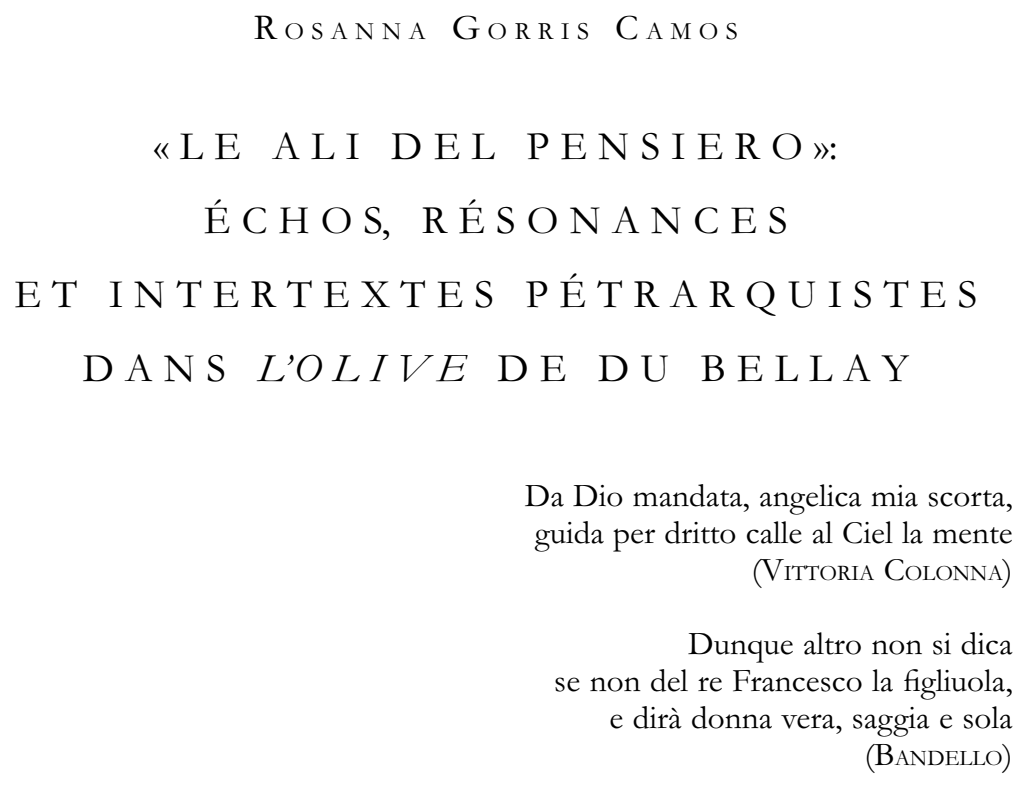

Una rosa è una rosa è una rosa è una rosa 



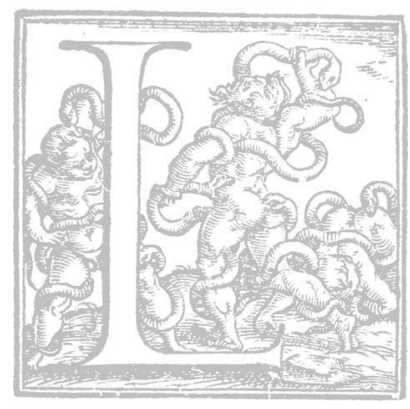

es «sainctz, rameaux》 (s. 6I, 2) de l'Olive, on pour le dire avec Vittoria Colonna, les «Rami d'un arbor santo» (s. I7 $)^{\mathrm{I}}$ composent un dessin complexe, difficile à «districare», à éclaircir; des échos intertextuels divers résonnent dans les vers de ce recueil à la saveur douce et amère, où les voix des Muses se rencontrent et se mêlent en concert. Si tout discours sur l'intertexte et sur le lexique de l'Olive ne peut se soustraire à une réflexion sur le pétrarquisme et sur son code: «ogni discorso sull'Olive non potrà che interrogarsi, in primo luogo sul rapporto col modello che per comune consenso è il Canzoniere di Francesco Petrarcas, a justement écrit Guglielmo Gorni, ${ }^{2}$ nous partageons son avis quand il affirme que «il petrarchismo non basta», ${ }^{3}$ que ce concept est insuffisant pour évoquer les couleurs diverses, la douceur des paysages, la dulcedo bumaniste, mais aussi les complexités de ce recueil issu des «targues palladiennes» et qui reflète, comme un miroir, les inquiétudes spirituelles de Marguerite et de son savant entourage.

Pétrarque intertextuel ou l'arbre de l'Olive

Un recueil qui, comme les Fiamme du ferrarais Giovan Battista Giraldi Cinthio, né à l'ombre de Renée et d'Hercule d'Este, ${ }^{4}$ est et veut être un livre (et non une anthologie) savamment construit et évoque une fiction poétique, un journal («diario») philosophique et existentiel qui, tout en orchestrant la koiné, chère aux néopétrarquistes des anthologies de Giolito, patiemment lues et annotées par les membres de la Pléiade (il suffit de voir l'exemplaire annoté par Ronsard où il marque, à côté des sonnets imités par Du Bellay, "Bellay»), se nourrit à la source d'autres modernes italiens, les auteurs des Rime: l'Arioste bien sûr, ${ }^{6}$ mais aussi Alamanni, Bembo (cf. s. 24, s. I09 «toy, qui du ccur les abismes connoist»), ${ }^{7}$ Giraldi, Bandello, ${ }^{8}$ sans oublier le poète et théologien Marcantonio Flaminio.' Vittoria Colonna et Veronica Gambara, «sono con loro» et, nouvelles «Laura e Beatrice» (s. I7), «fanno capolino», font irruption dans le texte et dans l'intertexte de Du Bellay et participent à cet élargissement des confins, à cette symphonie 
des couleurs et des lexiques différents. Le fil blanc du néopétrarquisme amoureux se teint des couleurs ronges des Rime spirituali; le vert pâle de l'Olive, évoquant les paysages de Fontaine de Vaucluse, semble s'enflammer et s'obscurcir, «le cep lascif» se métamorphose en «l'alma sacra Vite», "vivo ramo», ${ }^{\mathrm{IO}}$ pour devenir, enfin, dans une sorte de "dessèchement progressif» (l'adjectif «sec» présente s récurrences dans le recueil) ${ }^{\mathrm{II}}$ qui va connoter le recueil de I552, magnifiquement édité, en I98I, par notre maître Tina Caldarini, peu avant sa mort, ${ }^{12}$ les bras nus de la Croix.

Le «dolce-amaro» de Pétrarque se lie ainsi à l"«amaro lagrimar, non dolce canto» des Rime de Colonna. ${ }^{{ }^{3}}$ L'Olive a un goût, "générateur et porteur d'une esthétique ambiguë, quasi gustative» ${ }^{\mathrm{I}}$ (Du Bellay même, dans le paratexte de I552, définit ses poèmes «savoureux»); ${ }^{\mathrm{I}}$ "L'olivo è dolce, l'oliva è amara», écrit le poète. ${ }^{16}$ Une esthétique et un lexique du «dolce-amaro» sous-tend le recueil de Du Bellay qui nous ramène à Pétrarque qui écrit, ne l'oublions pas: «Non lauro né palma, ma tranquilla oliva / Pietà mi manda», mais aussi aux Rime de Vittoria, ces mêmes Rime que l'ambassadeur des Este, Alberto Sacrati, avait fait parvenir, via le secrétaire de Bembo, Carlo Gualteruzzi, à Marguerite de Navarre et dans lesquelles, selon Montmorency, "v'erano di molte cose contro la fede di Gesù Christo». ${ }^{17}$

Vittoria émaille en effet ses sonnets, qui circulaient dans de nombreux manuscrits dans son entourage ${ }^{18}$ et publiés en recueil, ${ }^{19}$ à partir de 1538 (I539 et I539 ${ }^{I-2-3} ; 1540^{I-2} ;{ }^{20}$ I542 $2^{I-2}$; I543; I544; I546 ${ }^{I-2} ;$ I5 $48^{I-2}-$ deux exemplaires de l'édition de 1548 des Rime spirituali de Vittoria Colonna, Venise, Comin da Trino, et un exemplaire Venise, Valgrisi, I546, ${ }^{2 \mathrm{I}}$ sont d'ailleurs conservés à la B.N. de Turin, où nous avons retrouvé de nombreux ouvrages ayant appartenu à Marguerite de France), ${ }^{22}$ de l'adjectif "amaro», souvent en rapport dialectique avec l'adjectif «dolce» et aussi associé, comme chez. Du Bellay (s. 45, v. I2 et s. 93. v. I4), aux substantifs «frutto» et «radice». Nous citons ici quelques exemples:

Se 'l commun Padre, or del Suo Cielo avaro, m'asconde voi, miei lumi, e lui, mio sole, l'Altro immortal, cui l'alma adora e cole, scorge ella più che mai lucente e chiaro, 


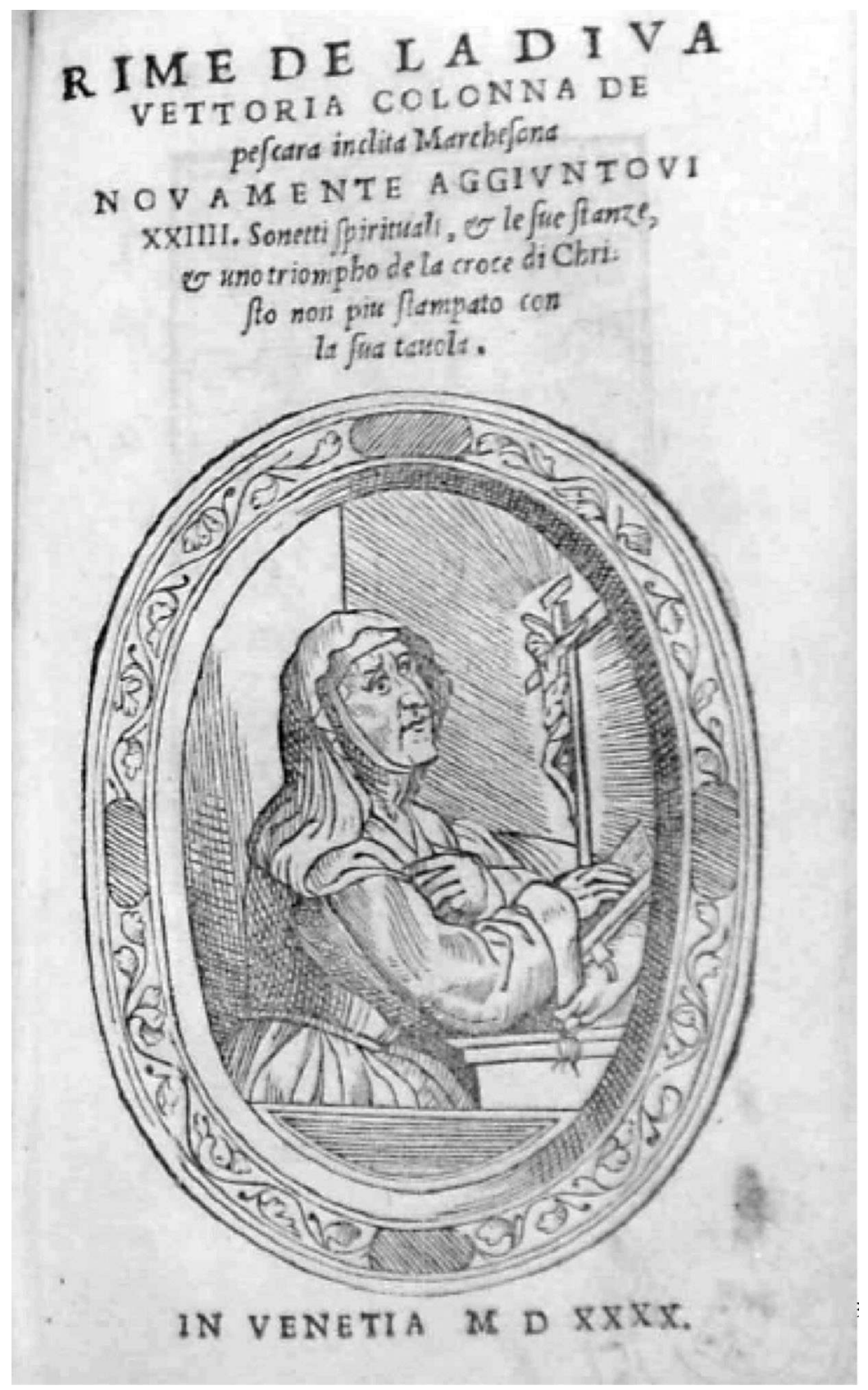

FIG. I. 
e del Suo vivo raggio, ardendo, imparo che non quel dolce che qui il senso vole è buon cibo per noi, ma quel che sòle esser al gusto più noioso e amaro;

perché de l'alta luce oggi un bel lampo venne lieto, e sgombrò quante al mio core erano folte nebbie avolte intorno,

e, mentre ei splende, io di desire avampo d'aver pur notte agli occhi altrui di fore per veder dentro in me lucido giorno. ${ }^{23}$

Sovra del mio mortal, leggiera e sola, aprendo intorno l'aere spesso e nero, con l'ali del desio l'alma a quel vero Sol, che più l'arde ognor, sovente vola,

e là su ne la sua divina scola impara cose ond'io non temo o spero che 'l mondo toglia o doni, e lo stral fero di morte sprezzo, e ciò che 'l tempo invola, ché 'n me dal chiaro largo e vivo fonte ov'ei si sazia tal dolcezza stilla che 'l mel m'è poi via più ch'assenzio amaro,

e le mie pene a lui noiose e conte acqueta alor che con un lampo chiaro di pietade e d'amor tutto sfavilla. ${ }^{24}$

Così tacendo 'l mal cresce più forte, come ancor la radice del mio amaro, celando la cagion del mio languire. ${ }^{25}$

$$
58
$$

Quel fior d'ogni virtute in un bel prato con l'aura de la mia gioiosa speme tal odor mi die' già che 'l dolce seme fa il frutto amaro ancor soave e grato. ${ }^{26}$ 
né per il frutto amar ch'ognor ne colsi

l'alta cagion men cara al cor mi riede. ${ }^{27}$

Nouvelle vision ou nouveau visage du néopétrarquisme

On pourrait multiplier les exemples de convergences lexicales qui associent l'Olive aux Rime de Vittoria, à partir du lexique de l'absence de l'être aimé, la récurrence des paroles ailées (ali, volo, penne), du mot fede / foi, du mot core / cœur, de la présence de métaphores végétales, ${ }^{28}$ de l'arbre esleu, de paysages de l'âme et du lexique de la croix des derniers sonnets. Or, le lexique néopétrarquiste et néoplatonicien de l'Olive peut acquérir une nouvelle dimension spirituelle, mais aussi poétique, si on le lit à la lumière des Rime spirituali et du renouvellement poétique qu'elles ont engendré. Miroir d'une crise, d'une dualité profonde (et Vittoria, par ses recueils, souvent organisés en Rime amorose et spirituali, par les éditeurs, est la meilleure incarnation de cette ambivalence ou «bivalenza»). Pour R. Fedi qui parle de Vittoria comme d'une "figura bifronte», ${ }^{29}$ «divisa», "divaricata», le poète est lui aussi «alla ricerca spasmodica di un'immagine vera, di una rivelazione, di un'epifania che desse un senso al Canzoniere». ${ }^{30}$ Il s'agit de signes et d'index textuels souvent lexicaux (de marqueurs du texte) qui vébiculent une diverse et plus complexe vision du code pétrarquiste, non seulement du point de vue géographique (le pétrarquisme est un phénomène incontestablement européen, ainsi que l'a confirmé le beau colloque de Venise, European Petrarchism. Reading and Writing Petrarch in the Renaissance, organisé par Stefano Jossa dont les Actes paraissent dans ces deux numéros de Italique. Poésie italienne de la Renaissance, revue fondamentale pour les études dans ce domaine), ${ }^{3 \mathrm{I}}$ mais aussi spirituel et métatextuel et englobant, en tant que code de communication, différentes modalités de relations. La critique a bien mis en évidence (cf. Les études récentes de Amedeo Quondam - dont l'équipe avait préparé, en 1997, un Archivio della tradizione lirica da Petrarca a Marino, Amedeo Quondam dir., Lexis 1997 qui publie 200 livres de Rime numérisés - sur la poésie religiense de Pétrarque au Tasse, ${ }^{32}$ de Italo Pantani, Libri di poesia $^{33}$ qui recense tous les recueils de Rime de I470 à I600, d'Anto- 
nello Corsaro sur Michelangelo, de Carlo Ossola sur Colonna dont il a mis en évidence l'intertexte et l'inspiration valdésienne ${ }^{34}$ la nécessité de redessiner la topographie du pétrarquisme, en tant que magnifique instrument, code de communication moderne pour dire, pour communiquer les passions de l'âme, le tourment amoureux, mais aussi la conversion ou la pietà. "Strumento comunicativo delle relazioni interpersonali, codice primario dello scambio formalizzato, palestra ordinaria della scrittura di corrispondenza o di occasione», selon A. Quondam, le pétrarquisme parvient à englober diverses dimensions, diverses expériences existentielles et artistiques (en ce qui concerne les relations avec l'art, les poèmes de Michelangelo, écrits à l'ombre de Vittoria, "figura altera, immagine vera», en sont un exemple splendide). ${ }^{35}$ Il présente, en tant que code de la modernité, des enjeux sociaux ("contrassegno del nuovo gentiluomo») et culturels, en tant que vecteur et facteur de la deffense et illustration d'une langue et d'une identité nationale.

\section{«Per l'exempio d'Elia»: évangélisme et poésie}

Dans Le Rime de Vittoria les convergences lexicales et thématiques avec l'Olive sont si nombreuses et si importantes que nous pourrions citer de longues listes d'exemples et de récurrences pour démontrer comme la pasle couleur des poèmes de la nuit et de l'âme (deux champs lexicaux importants de l'Olive) ${ }^{36}$ de Vittoria, enveloppés par un voile (les récurrences du mot velo sont frappantes, on en retrouve au moins trente dans l'édition Bullock) $)^{37}$ de brume - comme le magnifique sonnet 13 des Rime d'amore disperse ${ }^{38}-$ semblent enchanter le poète de l'Olive, «pasle, dessoubz l'arbre pasle etendu» (s. 45, v. II). Virgile donc, sans doute, comme l'a brillamment démontré Olivier Millet, ${ }^{39}$ mais aussi Vittoria qui, de son refuge à la douleur de la mort de son mari, l'Ile d'Ischia [fig. 2 portrait de Vittoria Colonna, MNAC Museu Nacional d'Art de Catalunya, buile sur bois, $96 \times$ 72.5], regarde au loin et introduit dans une nouvelle alliance entre lexique pétrarquiste de l'absence de l'être aimé et lexique spirituel, le thème d'Élie, qui sera si cher, ainsi qu'on le sait, aux poètes du Tombeau de Marguerite de I5s I et donc à Du Bellay qui fait voler, dans la nuit sereine, «le grand Prophete» et «l'Esprit du corps devoilé», «jusques au ciel», où «treluisent» les étoiles «epoinçonnées»: ${ }^{40}$ 
Quando io dal caro scoglio guardo intorno la terra e 'l mar, ne la vermiglia aurora, quante nebbie nel ciel son nate alora scaccia la vaga vista, il chiaro giorno.

S'erge il pensier col sol, ond'io ritorno al mio, che 'l Ciel di maggior luce onora; e da questo alto par che ad or ad ora richiami l'alma al suo dolce soggiorno. [heureux séjour]

Per l'exempio d'Elia non con l'ardente celeste carro ma col proprio aurato venir se 'l finge l'amorosa mente

a cambiarmi 'l mio mal doglioso stato con l'altro eterno; in quel momento sente lo spirto un raggio de l'ardor beato.

Nouvelle Béatrice, la consolation arrive sur les ailes de ce char céleste pour changer la douleur toute humaine de l'absence, «il mio mal doglioso stato», en ravissement et en "ardor beato». La pensée «s'erge», s'élève vers le ciel, l'âme retourne à son «dolce soggiorno». "Oggi» est le mot-clé de ces Rime où la douleur de la mort de l'être aimé devient méditation et poésie du Christ.

\section{Le ali del pensiero}

Or, dans l'édition de Tutte le rime della illustrissima et eccellentissima signora Vittoria Colonna, Marchesana di Pescara, con l'espositione di Rinaldo Corso (un exemplaire est conservé à la bibliothèque Civica de Vérone, Cinq. F. 897), l'éditeur et commentateur Rinaldo Corso, ${ }^{41}$ membre de la cour de Correggio qui se réunissait autour de Veronica Gambara (et, naturellement, ce n'est pas un hasard si Du Bellay, ainsi que nous l'avons suggéré ailleurs, reprend deux sonnets de la dama de Correggio et, notamment, le célèbre s. II2 $)^{42}$ a réuni les sonnets en microséquences thématiques. Or, l'une des plus importantes comprend les sonnets 89-I02 (I3 sonnets) qui, presque tous, contiennent dans les premiers vers le mot pensiero (autre mot-clé du lexique colonnien) et orchestrent le thème de l'envol. Dans ces sonnets du pensiero qui nous montrent la femme-poète, ravie au ciel, 


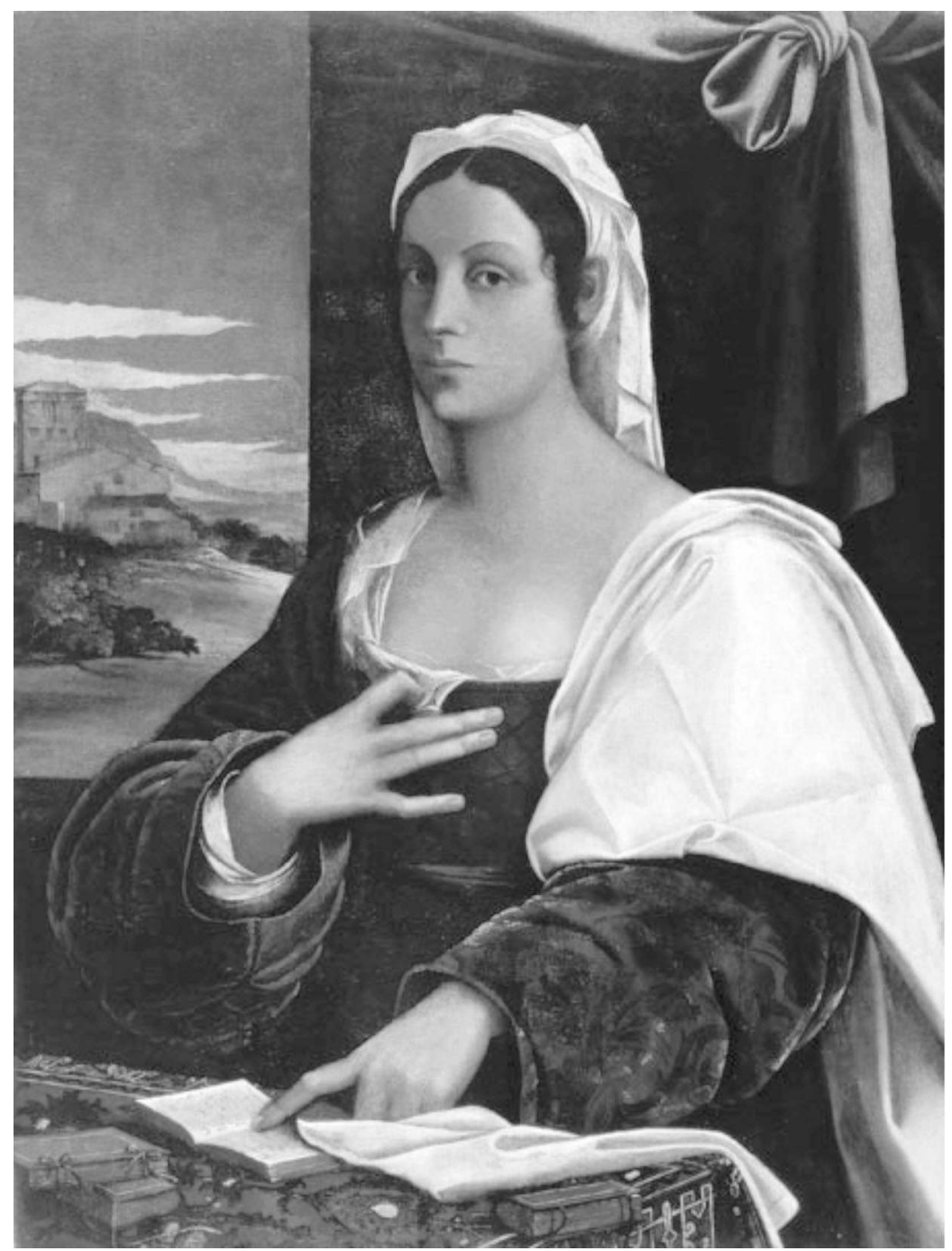

FIG. 2.

Portrait de Vittoria Colonna

MNAC Museu Nacional d'Art de Catalunya

en contemplant la réalité céleste, le mot est toujours associé à l'une des paroles ailées qui vont faire irruption dans l'Olive de I550:

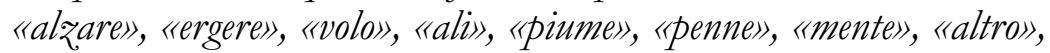

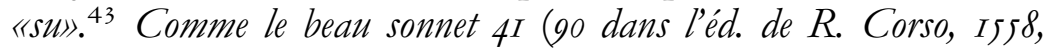
f. $\left.I I V^{\circ}\right)$ : 
Alzata al Ciel da quel solingo e raro pensier che sovra il corso uman mi spinge veder mi parve il volto che dipinge Amor al cor, ma più splendente e chiaro;

e udir su questi cerchi or lieto imparo come un solo voler li move e cinge, com'una sola mano allarga e stringe quanto piove fra noi di dolce e amaro.

L'intelletto, tra il lume e le parole, d'un'altra meraviglia sovraggiunto, fiso nel mio non scorse il maggior Sole;

perché già al fin del desiderio giunto non sofferse la gloria, onde mi dole che giunger e sparir fosse in un punto. ${ }^{44}$

Pensier, ne l'alto volo ove tu stendi l'audaci penne il mio valor non sale; onde perder l'impresa ed arder l'ale sarà il fin del principio ch'ora imprendi.

Poi con l'ardito vaneggiar m'accendi, sì ch'io consento il bel Lume immortale mirar con l'occhio mio debile e frale che 'l vigor perde ove tu sol ascendi.

Desir, non aspirar al gran dissegno, ché da radice è svelta mia speranza, volto è in contrario ogni benigno lume.

Arde il cor pur senza mostrarne un segno: ascondasi il martir ch'ogn'altro avanza; alma, taci ed adora il sacro Nume.

(s. 92 éd. Corso, I 558 , f. 29 r $)^{45}$

Dans son commentaire, ${ }^{46}$ dédié à Veronica Gambara (les rapports entre Veronica et Vittoria qui échangent des poèmes et dont parfois les éditeurs ont confondu les sonnets en publiant sous le nom de Colonna des poèmes de Gambara et vice-versa sont connus), ${ }^{47}$ il explique ce qu'il définit la «metafora dell'ale»: "Platone disse, l'animo nostro aver 
due ale, lequali allegoricamente si prendono per lo doppio istinto della mente verso alle cose di sopra. Nell'intelletto è l'istinto che alla verità divina ci move. Nella voluntà quelle, che al bene di la su ci spinge. O diciamo, l'una virtù esser la virtù contemplativa, l'altra la morale.» (f. 4I2, s. 7 Spense il dolor la voce e poi non ebbe).

«Une certaine inspiration evangelique»: «quasi nuova Fenice»

Rinaldo Corso, dont le commentaire présente, selon nous, un grand intérêt, ${ }^{48}$ ajoute aussi au s. 32, I4 Chi non ammira sì nova fenice (s. 85, éd. Corso) un long et plaisant commentaire sur le Phénix, ${ }^{49}$ un autre animal du bestiaire de l'Olive évoqué dans le sonnet 36 où il incarne le poète «faché de vivre» qui attend de «renaistre»: ${ }^{\circ}$

L'unic oiseau (miracle esmerveillable)

Par feu se tue, ennuyé de sa vie:

Puis quand son ame est par flammes ravie,

Des cendres naist un autre à luy semblable,

Et moy qui suis l'unique miserable,

Faché de vivre une flamme ay suyvie,

Dont conviendra bien tost que je devie,

Si par pitié ne m'etes ecourable! [...]

Puis qu'ay pour toy du Phenix le semblant,

Fay qu'en tous poinctz je luy soy'resemblant.

Tu me feras de moymesme renaistre. ${ }^{\text {I }}$

32

Quando più stringe il cor la fiamma ardente corro a l'alme faville ond'esce il foco; ivi più ognor m'accendo, ivi m'alloco e per sì dolce ardor l'alma il consente. D’appressarsi al suo mal rimedio sente, sprezza il martir per apprezzar il loco, a la cagion si volge, e prende in gioco il grave duol de l'affannata mente. Nasce dal vivo lume un raggio tale che di ricca speranza ognor m'adorna, e poi mia fede un lieto fin predice. 
Chi non adora un valor senza equale?

Chi non contempla un Sol che sempre aggiorna?

Chi non ammira sì nova fenice?

17

Molza, ch'al Ciel quest'altra tua Beatrice

scorgi per disusate strade altere,

tal esser den l'immortal glorie vere:

gran frutto eterno trar d'umil radice.

Lieve fòra cantar ch'una fenice

vive, e ch'han lume le celesti spere;

far bianchi i corvi e le colombe nere

opr'è sol del tuo stil chiaro e felice.

Più onor che l'altro avrai, ché quell'al Cielo

trasse l'amante, e fuor d'umana scorza

li accese a l'opra santa il bel desio;

m'a te convien di casto ardente zelo

prima infiammar l'obietto, e quasi a forza

poscia condurlo fuor d'eterno oblio.

qui arrête longuement l'attention du commentateur et qui revient plusieurs fois dans les Rime de Colonna, «quasi, dit-elle, nova Fenice» qui passe par le feu de l'amour pour renaître en Christ (cf. le s. I7 ci-dessus, sonnet à Molz̧a, où elle évoque les «disusate strade» qui rappellent le "sentier inconneu» du s. I v. I et l" "aele inusitée», s. II4 v. I4).

Nous avons d'ailleurs retrouvé à la Bibliothèque Royale de Turin le manuscrit de dédicace à Marguerite (BRT, Var. 65) ${ }^{\text {s2 }}$ et une édition (BRT, Varia I03) de l'ouvrage de Guy de La Garde Chambonas, L'histoire et description du Phoenix. ${ }^{3}$ Un ouvrage que l'auteur, fidèle serviteur de la princesse (f. 2), avait offert à Marguerite «non pour aucune grace, faconde ou eloquence, qui fussent en luy: mais plustost, pour certaine inspiration evangelique laquelle ne m'induisit pas seulement à le composer et luy dedier: mais aussi m'incita, de le presenter à la majesté, comme seul singulier et unique Phoenix ou mieulx, trescler et reluysant miroer sans macule, et tresdigne exemplaire, de toutes genereuses, sçavantes et vertueuses Princesses et Dames» (f. Aii). Une inspiration qui, nourrie d'un «sainct propos divin evangelique» (f. Biïj $\left.{ }^{\circ}\right)$, souffle puissante sur tout l'ouvrage, émaillé de poèmes en 


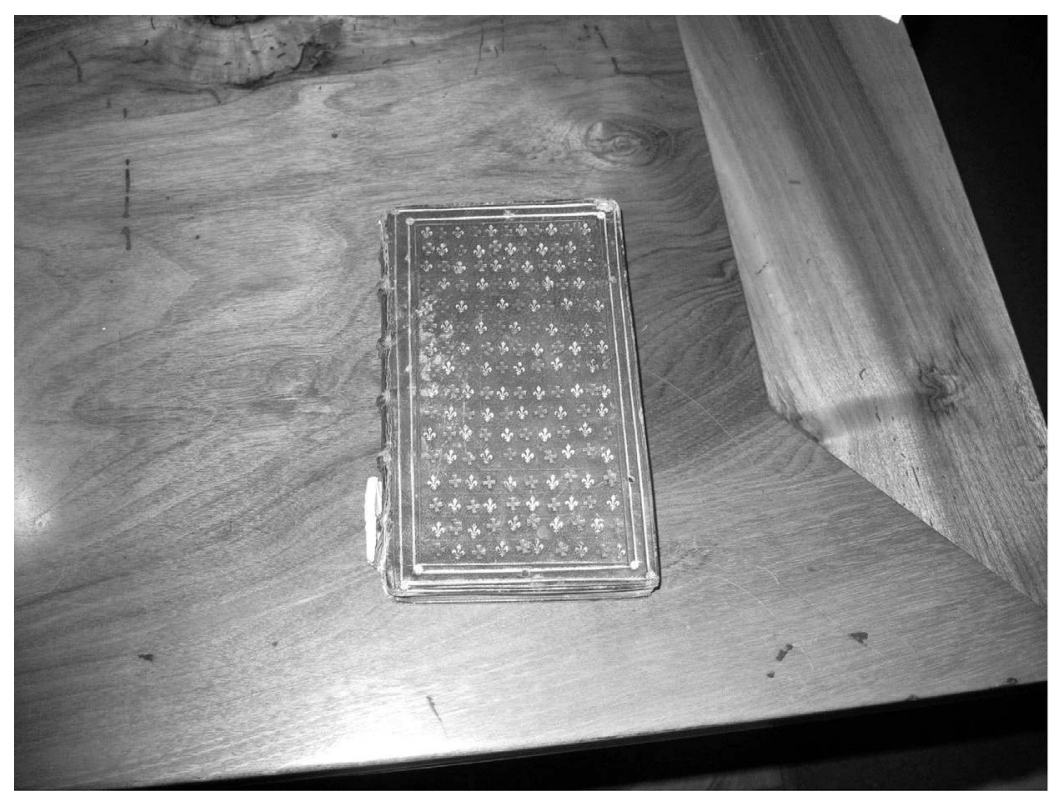

FIG. 3.

BRT de Turin, Ms. Varia I03

l'honneur de Marguerite, dont l'anagramme, De vertus ay ma gloire, revient comme un refrain dans ces pages d'hommage dévoué. ${ }^{54}$ Sa dévotion à la princesse va d'ailleurs augmenter, au fil des années, pour trouver son sommet dans le manuscrit que nous avons retrouvé de Le destin du tresheureux et passificque mariage de treshaut, trespuissant, et tresillutre Philibert Emanuel Duc des Savoye et Prince de Piemont par l'aucteur de l'histoire du phoenix. $C e$ don de mariage se trouve dans un recueil de trois ouvrages, deux imprimés et un manuscrit, que ce protégé de Marguerites a fait relier en cuir en semé de fleurs de lys et de croix, emblèmes des deux mariés (fig. 3, BRT de Turin, Ms. Varia I03).

«Et egli a lei un bellissimo disegno d'una Pietà mandò, da lei chiestoli»: le «dolce Cristo vivo» de Vittoria

Toutes ces affinités lexicales, ces convergences, voire ces résonances relèvent des complexités qui enrichissent et nuancent la notion de pétrarquisme («il petrarchismo non basta», a justement écrit Gorni dans son 
bel article sur le calendrier de l'Olive), mais sont aussi le signal de connivences spirituelles, un «comune sentire» et une «inspiration evangelique» que les recherches en cours sur les réseaux de l'évangélisme italien, dont les ramifications entre France et Italie restent encore pour la plupart à explorer, peuvent nous aider à comprendre, à «sonder». Le rapport de Vittoria avec Marguerite de Navarre, par exemple, n'est pas encore clair, même si plusieurs documents conservés aux Archives $d u$ Vatican ont été publiés par M. Pagano et C. Ranieri. ${ }^{56}$ Il s'agit notamment d'un Quinternus litterarum quondam Illustrissimae Dominae Marchionissae Piscariae et aliarum (Stanza storica E-2-e) qui contient des lettres: une lettre à Marguerite de Navarre, deux lettres de Marguerite, une à Vittoria Colonna, l'autre à Georges d'Armagnac. Ces lettres confirment donc ce rapport qu'Eleonora Belligni a défini de "ssorellanza contrastata», ${ }^{57}$ mais aussi le fait que leurs lettres furent confisquées par les autorités ecclésiastiques. L'édition du Vangelo de San Matteo de Valdès par Carlo Ossola ${ }^{58}$ et le livre récent de Maria Forcellino, Michelangelo, Vittoria Colonna e gli "spirituali". Religiosità e vita artistica a Roma negli anni Quaranta, ${ }^{59}$ qui met en lumière les dessins de la Crocefissione (London, British Museum) et de la Pietà (Boston, Isabella Stewart Gardner Museum) que Michelangelo exécuta pour Vittoria, ont révélé de nouvelles directions de recherche: les rapports entre Michelangelo et la marquise, la présence de ce "corpo vivo», "un corpo che rappresenta mirabilmente il processo di umanazione del Dio fatto uomo» et qui renvoie à une «religiosità fortemente cristologica». ${ }^{60}$ Il serait impensable de saisir les nouveautés iconographiques de ces deux dessins de Michelangelo, faits pour Vittoria, sans comprendre la ferveur, l'effervescence du renouvellement théologique qui caractérise ces années. Vittoria admire la "gratia soprannaturale a far questo Christo» de l'artiste et se demande comment participer à ce chef-d'cuvre de la foi chrétienne: «et in quel mezzo io non so come servirvi in altro che in pregarne questo dolce Christo, che si bene et perfettamente havete depinto». ${ }^{\text {G1 }}$ Elle lui écrit:

Unico maestro Michelangelo et mio singularissimo amico. Ho hauta la vostra e visto il crucifixo, il qual certamente ha crucifixe nella memoria mia quale altri picture viddi mai, né se pò veder piu ben fatta, più viva e più finita immagine et certo io non potrei mai explicar quanto sottilmente et mirabilmente è fatta, per il che ho risoluta de non volerlo di man d'altri. ${ }^{62}$ 
Or, ces rapports de connivence spirituelle entre Vittoria Colonna et Michelangelo nous expliquent que l'interaction entre la poésie lyrique en vulgaire, les arts et les exigences pressantes d'un renouvellement spirituel est importante et nous permet de mieux cerner l'intertexte et le lexique des recueils des années I540, bien plus ou de façon différente de ce que de vagues renvois au néoplatonisme florentin ou au néopétrarquisme pouvaient le faire.

Les exigences d'une réforme morale sont si complexes et, comme Antonio Corsaro l'affirme pour Michelangelo, «la poesia volgare, e in particolare la poesia lirica considerata nelle sue strutture metriche e di genere e nelle convenzioni retoriche e stilistiche profondamente consolidate nell'epoca in oggetto, necessita uno studio distinto, rivolto al carattere più "infido" e meno riconoscibile dei messaggi》. ${ }^{63}$

Or, les études sur Vittoria Colonna et sur les milieux de l'évangélisme italien (cf. notamment les études de Barbieri et de Fragnito, mais aussi de Massimo Firpo et notamment Vittoria Colonna, Giovanni Morone e gli spirituali) ${ }^{64}$ peuvent permettre, parfois, d'éclaircir des messages que les conventions rhétoriques et stylistiques voilent. Le «tenebreux voile» peut devenir ce que l'on a récemment défini «allégories de la dissidence» (si répandues à la cour de Renée, son emblème étant Protée, et à la Cour de Marguerite de France) ${ }^{65}$ et l'étude du lexique et de la genèse des recueils (les cas de Colonna et de Michelangelo sont paradigmatiques), ${ }^{66}$ des variantes et des stratifications, dans toute leur complexité, permet d'expliquer ou d'éclaircir les «singolari aperture di un genere tradizionalmente laico a implicazioni spirituali e alla diffusione di messaggi religiosi specifici». ${ }^{67}$

Le «cangiato stile» de Vittoria - en I536, Carlo Gualteruzzi (toujours lui) envoie un sonnet de Colonna à Cosimo Gheri et écrit: «La Signora Marchesa di Peschara ha rivolto il suo stato a Dio, e non scrive d'altra materia, si come per l'inchiuso sonetto potrà vedere, il quale le mando per mostra di questo suo cangiato stile. Havrò caro che 'I facciate legger a monsignor Bembo et me ne scriviate il giudicio di sua Signoria» ${ }^{68}$ - qui est sans doute le résultat de «una svolta profonda, forse anche di una crisi che si verbalizza in poesia, tra volontà di silenzio, anzi di "oblio" di sé, e aspirazione invece a "miglior opre", a mutar $i$ proprii assunti lirici da fallaci in veri»," ${ }^{99}$ mais c'est aussi un signal d'un changement du canon, dans les années Is40 et qui aboutira à la publication, en I550, à Venise du Libro primo delle rime spirituali 
(Venezia, al segno della Speranza, I550) qui comprend une présence massive de poèmes de Vittoria Colonna. ${ }^{70}$ Ce nouveau recueil est l'indice révélateur d'un changement profond qui se reflète aussi dans la politique éditoriale des imprimeurs qui, comme le grand Giolito, ${ }^{71}$ vont publier «a tambur battente» ces rime spirituali, sorte de "grammaires" de la méditation, pour satisfaire aux nouvelles exigences du public. En I543, la Dichiaratione fatta sopra la seconda Parte delle Rime della Divina Vittoria Colonna Marchesana di Pescara, de Rinaldo Corso, vaste commentaire des poèmes de Vittoria dédié «a Veronica Gambara ed alle donne gentilis, dont on a déjà parlé, révélait, d'un côté, l'importance des Rime spirituali pour les lecteurs de l'époque, de l'autre les enjeux éditoriaux de cette nouvelle orientation poétique. En effet, même la présentation éditoriale de l'édition de I540 (celle qui contient le sonnet "Miser, che deb'io altro, che pianger sempre, I S'io miro la beltà, ch'in terra adoro», Rime, I540, f. 3I) focalise son attention sur la «giunta spirituale»: sur la page de titre une femme à genoux devant le Crucifix (cf. fig. I), au verso une autre image du Christ en croix entouré de personnages. ${ }^{72}$ Or, ces gravures évoquent les pages de titre des Prediche et des Dialoghi de B. Ochino (les rapports de Vittoria Colonna avec Ochino sont importants, à partir de ce thème fondamental, du «dono dall'alto», véritable «tesoro dall'alto» et le commun «disfidare in sé e nelle proprie opere», la «dolce e soave» présence de l'intervention du Christ, «vivo ne l'aspara croce il Signor vede» s. 59, éd. Bullock, p. II 4$) \cdot^{73}$

Les poèmes de Vittoria résonnent des accents des cuvres théologiques de Bernardo Ochino, probable «tramite naturale» entre la Marquise de Pescare et le cercle de Valdès. ${ }^{74}$ Une lecture des textes poétiques de Colonna à la lumière des écrits d'Ochino permet de retrouver de nombreuses affinités: la «luce inaccessibile», les «fiamme accese» du cour, le "transformarsi in Dio» à travers le mépris du monde, le «peregrinare» et l'aspiration à la vraie "patria», mais surtout la centralité absolue de la méditation sur la croix. ${ }^{75}$ Il suffit de lire le magnifique sonnet 74 , où nous retrouvons les mots-clés du lexique de Vittoria: le verbe «ergere» (《se bausser»)), ${ }^{76}$ le goût «aspro» («amer»), la tempête (autre allégorie chère à du Bellay et aux poètes de l'évangélisme français, comme Michel de l'Hospital qui l'orchestre dans ses magnifiques Carmina et, notamment, dans l'Iter Nicoeum, le récit de son voyage à Nice pour accompagner Marguerite) ${ }^{77}$ sous la forme de «oscuro e nero Nembo» 
(«tenebroso velo») qui s'oppose au «lume vero», à «la celeste pace», après le «terrestre affanno»:

Chi temerà già mai ne l'estreme ore de la sua vita il mortal colpo e fero s'ei con perfetta fede erge il pensero a quel di Cristo in croce aspro dolore?

Chi del suo vaneggiar vedrà l'orrore che ci si aventa quasi oscuro e nero nembo in quel punto, pur ch'al Lume vero volga la vista del contrito core?

Con queste armi si può l'ultima guerra vincer sicuro, e la celeste pace lieto acquistar doppo 'l terrestre affanno; non si dee con tal guida $\mathrm{e}$ sì verace, che per guidarne al Ciel discese in terra, temer de l'antico oste novo inganno.

Le sonnet 22 Felice giorno, a noi festo e giocondo des Rime spirituali, ${ }^{78}$ révèle une forte influence d'Ochino, qui sera traduit plus tard en français par un autre fedelissimo de Marguerite, Jacques Grévin, ${ }^{79}$ et présente des affinités troublantes avec le s. III de l'Olive, mais aussi avec le s. II4, quand Vittoria attaque le «mechant populaire», «e'l popol duro / quel divino parlar velato oscuro / intese mal col cor empio ed immondo»,, incapable de comprendre le «parlar velato oscuro», car l'homme ne sait comprendre la signification profonde du «Signor, quand'Ei fatt'uom qui vinse l'Inferno e'l mondo, di luce infinita lampeggiar sempre le virtù divine»:

22

Felice giorno, a noi festo e giocondo, quando offerse il Signor del sacro e puro corpo nudrirne, e render l'uom sicuro di star sempre con Lui nel cieco mondo, e che per tal virtù leggiero il pondo fòra de' nostri mali, e 'l popol duro quel divino parlar velato oscuro 


\begin{abstract}
intese mal col cor empio ed immondo; onde sol meraviglia e grande orrore diede al superbo quell'alta mercede di dar per nostro cibo a noi Se stesso, e solo a quei che l'odio con l'amore avean vinto, e la legge con la fede, il dono che dà vita al cor fu impresso. ${ }^{81}$
\end{abstract}

«Dessile un peu tes yeux»: la «vraie image» de la dame

Mais pour trouver la clé de ce «divino parlar velato oscuro» (s. 22 v. б), il faut ouvrir les yeux. "Ouvre l'cil, ouvre l'œill, exclame la Muse Uranie au Secrétaire de l'Encyclie des secrets de l'eternité. ${ }^{82}$ Sonnet important le s. II4, ainsi que E. Buron l'a justement mis en relief dans sa belle analyse où il évoque les rapports de ce texte avec la dédicace à Marguerite de France qui fait «voler» les poètes, ${ }^{83}$ un sonnet un peu mystérieux, mais où domine le lexique de l'apertio oculorum aux complexes connotations théologiques et mystiques. Encore une fois l'intertexte de Pétrarque (cf. le Triumphus aeternitatis, $v v$. Io-II: «chè la colpa è pur mia, che più per tempo / deve'aprir li occhi e non tardare al fine»), ${ }^{84}$ le «aprir li occhi» qui marque pour le poète des Trionfi la fin de la visio mystica, s'allie au lexique paulinien (Actes 26, I8) dans ce parcours de ré-vélation par lequel le visage de la femme aimée devient figura Christi: «car leur pensée s'est obscurcie. Jusqu'à ce jour en effet, lorsqu'on lit l'Ancien testament, ce même voile demeure. Il n'est point levé; car c'est le Christ qui le fait disparaître. [...] C'est quand on se convertit au Seigneur que le voile tombe» (Cor. II, 3. I4-I8).

Le visage de la dame chez. Pétrarque est transformé par la révélation, il n'est plus le visage cruel de la dame-Méduse, mais le visage d'une miraculeuse Veronica, ${ }^{85}$ un guide qui le mène vers le ciel par l'amour des lettres et le désir de Dieu: "Il volto di Laura non è più quello pietrificante (Medusa Rvf 366. II), ma di una miracolosa Veronica, una guida che lo conduce al cielo passando, nella storia, tra l'amore per le lettere e il desiderio di Dio». ${ }^{86}$ Le visage de la dame, devient «vera icona», et nous revenons au Tombeau de Marguerite où, dans la dédicace $\left[f\right.$. Aiir $\left.{ }^{\circ}\right]$, Denisot orchestre le lexique de l'immortalité et le 
lexique de la «vraie image»: "Ici est tellement au vif representée la vraie image de nostre Marguerite la voyant aujourd'buy si vivement vive apres sa mort». ${ }^{87}$ Un motif très important que celui de la «vera icona», vraie effigie ("vero ritratto» di Dio», écrit de Mesmes dans sa version di distique 86) qui sous-tend le lexique du Tombeau et qui est repris par Du Bellay et par les autres:

\section{Distique 86}

Quis speculum illius non admirabitur, in quo

Vera DEI effigies illa refracta datur?

J.-P. De Mesmes

Chi non ammirar lo Specchio intatto

Di questa nobil Regina? dal quale

Verso noi tutti reflette e risale

Del'Iddio vero, un vero ritratto.

I.D.B.A.:

Qui n'admire son MIROIR

Qui rend toute Ame asseurée

De son DIEU, luy faisant voir

L'image reverberée?

Denisot

Qui est cellui qui n'admire

Son miroir, ou en tout lieu

La vraie image de DIEU

Imprimée se remire.

$$
\text { (f. } \text { Giir }^{\circ} \text { et v }{ }^{\circ} \text { ) }
$$

Distique 93

I.D.B.A.

Tu portes du DIEU vivanT

Sur ton front l'Image Saincte

Nul mal ne t'ira grevant

Aiant telle Enseigne emprainte.

$$
\text { (f. } G 5 v^{\circ} \text { ) }
$$

JPDM

Tu porti o donna nella fronte lata, Dell'Iddio vivente il grande Suggello. 
Onde nessun tedio, quantunque fello,

Po nocer alla Donna suggellata.

(f. $\mathrm{G} 5 \mathrm{v}^{\circ}$ )

"Imagin viva» que l'on retrouve dans le sonnet 4 de Vittoria:

Alma felice, se 'l valor ch'excede

nel mondo ogn'altro ancor nel Ciel sublima,

come in le nobil menti sei la prima

esser de' tua la più pregiata sede.

Finché l'imagin viva a l'occhio riede

la bella tua memoria in l'alta cima

di quei degni pensier ch'han vera stima

farà de l'opre chiare immortal fede,

ché né invidia qua giù, né là su merto,

di fama al mondo, e al Ciel di gaudio eterno

l'ultimo pregio a la tua gloria tolse.

Ragion l'afferma e Amor me 'l mostra aperto

che 'l tuo vivo splendor riluce interno

nel petto, ov'ogni error prima disciolse. ${ }^{88}$

Terre et ciel, amour et mort, vie et mort, nuit et jour, avenglement / yeux ouverts, le tourment et les larmes, sont les métonymies d'un parcours et de topoi existentiels et poétiques; par ces cicatrici, tout est transfiguré en «imagin viva», "figura altera», Leitmotiv des sonnets de Michelangelo (s. 50) et de Vittoria. ${ }^{89}$ Méduse (grâce aux armes de Pallas?) est devenue Béatrice. La pierre, «imagin viva», est une mot-clé du lexique de Colonna, de Michelangelo et de leurs «frères en véritê». ${ }^{\circ}$ Tout devient «ricerca spasmodica di un'immagine vera, di una rivelazione di un'epifania che dia un senso al Canzoniere». ${ }^{\text {II }}$ Il fallait donner un sens au recueil, la femme senhal ne suffit plus. Vittoria Colonna est "figura di questa lacerazione», l'icône d'un débat poétique en cours et incarne cette recherche acharnée, spirituelle, mais aussi métatextuelle, d'une «imagin vera» qui substitue celle du personnage central, de la femme aimée. Le poète a ouvert les yeux, il a compris, comme le grand sculpteur, "la frammentarietà et la frattura irriducibile».92 Le pétrarquisme ne suffit plus, «non basta», il fallait réfléchir sur sa poésie et sur celle des autres.

Mais si pour Michelangelo, Vittoria Colonna est sans doute "figura altera», "Musa pensosa e seria e serena», pour du Bellay, sa Pallas- 
Olive qui n'a pas encore choisi comme emblème le saule, pleurant loin de l'eau (ses poètes?), «sa Déesse» (s. II4) ou «divine image», celle qui «tient le vol de son esprit», est et sera Marguerite. Le Soleil, senhal de Vittoria, devient celui de Ronsard, de ce poète qui paraît avoir volé le feu $d u$ divin flambeau, mais tous ces points d'interrogation, ces épithètes de l'envol audacieux: "divin, beau, audacieux, eternel, superbe», révèlent que le serpent de l'hybris pouvait être un danger pour ceux qui osaient voler trop haut. Le large tombeau recèle une menace voilée, ainsi que Tina Caldarini l'a écrit dans le paratexte de la Monomachie de David et Goliath (et là le jeu devient encore plus clair).

\section{«Cangiato stile»: le nouveau visage}

Mais pour revenir à Du Bellay et à son lexique si divers entre I549 et I5so, le «cangiato stile» de Vittoria a-t-il eu une influence sur l'évolution de l'Olive entre I549 et I550? Tous ces froissements d'ailes, cet élan vers le haut, la sequela Christi, ces «chiaro-scuri» (cf. ces notturni et ce soleil ariostesque: le Soleil - «sol, sole» - est le senhal de Vittoria, comme l'"Olive» pour Du Bellay et pour Marguerite) qui connotent l'Olive et son paysage, mais aussi les sonnets de Colonna où la lumière de l'ile d'Ischia et de ses plages ensoleillées (cf. le beau portrait de Sebastiano del Piombo) ${ }^{93}$ devient souvent «fredda, notte oscura», «notte profonda》 ("rmutossi in notte oscura il di sereno», s. 3 ข. б):

«Sono il Principio e parlo a voi mortali», dice il Signore, «e son del mondo il Sole, la vera Vite, ch'unir seco vole tutti i fedeli e farli alti immortali.

Sono il Pastor su le cui spalle i mali premon del caro ovile, e sol mi dole ch'errando vada ognor, pur come ei sòle, lungi da me coi piedi infermi e fralì.

S'Egli è Pastor, Principio, Lume e Vita, che guida $\mathrm{o}$ fine avrà, luce o salute, chi non ha Seco l'alma in pace unita? 
Entrar devrian come saette acute le Sue parole in una mente ardita che viver può dentro la Sua virtute.

(éd. Bullock, p. I 80)

Ce «doulx torment» (s. III v. 5), ces plaies et ce sang, comme les «belle cicatrici» ${ }^{94}$ de Vittoria où la nostalgie de l'bumain, la «memoria», mot récurrent de son lexique, 95 troublent le lecteur. Absents de l'Olive de I549, ces mots réorientent le recueil de I550. Or, ces mots de la douleur sont-ils influencés par le néoplatonisme florentin ou s'insèrent plutôt dans un mouvement plus vaste qui, à partir du Petrarca spirituale et des Rime de Vittoria Colonna, marque une sorte de «svolta epocale» (Barbieri) et naît d'exigences profondes de changement et de renouvellement spirituel que l'entourage de Marguerite ressent aussi profondément? Si Du Bellay, ainsi que Jean Vignes l'a justement écrit, "n'est pas exactement le même en mars I 49 et en octobre Is $50 »,{ }^{96}$ si le lexique de l'Olive de Is 50 est si différent de celui de l'Olive de I549, tant que Gorni en parle comme «il frutto di una poetica nuova», ${ }^{97}$ que s'est-il passé?

Si l'on a mis justement en évidence l'influence du clan du Bellay, ${ }^{98}$ un autre clan (qui n'est pas d'ailleurs sans lien avec le premier), celui des poètes italiens et français entourant Marguerite, a bien probablement orienté le poète vers le christocentrisme des sonnets finals, nourris d'une flamme sacrée qui va connoter d'ailleurs aussi les versions de du Bellay (ainsi que celles de Denisot, of. par ex. le distique 5s, dans lequel il ajoute la présence du Christ, absent de la version latine: "Pour prendre en JESU CHRIST / Les armes de l'Esprit») des distiques des sæurs Seymour publiées dans le Tombeau de IssI. ${ }^{99}$ Des textes où brûle la même flamme de la gerbe finale de l'Olive, où les poètes rivalisent pour évoquer la présence de la Reine, saur spirituelle de Vittoria et de sa nièce Marguerite à laquelle le recueil est dédié, ${ }^{\text {Io }}$ autre figura altera et «image vive» (les épithètes «vifi,, «vive», le verbe «vivre», représentent une véritable obsession de Du Bellay dans ses versions) ${ }^{\text {Iо I }}$ qui, "ame vagabonde» (distique 39), lasse de cet «ennuieux sejour» (distique 48), de son «exil [...] en ce bas estre» (distique $7 I$ ), après avoir "perdu les vains desirs de la vie miserable», vola au ciel pour «voler / admirable en l'univers / de l'un jusqu'à l'autre pole» (distique 32) et vivre pour l'éternité en Christ «pour à Dieu seulement vivre» (distique 43): 
I.D.B.A.

Dessous CHRIST sa vie fut, La mort soubs CHRIST l'a ravie: Ainsi voila comme elle eut Sous CHRIST sa mort et sa vie.

(f. Diiijr ${ }^{\circ}$ )

50

I.D.B.A

Ell'mourut, mais sous la foy De CHRIST, CHRIST vive elle adore:

Car (ô CHRIST) mourir en toy, C'est (CHRIST) en toy vivre encore.

$$
\text { (f. } \mathrm{D} 8 \mathrm{v}^{\circ} \text { ) }
$$

Le Comte d'Alsinois

Ell' bruloit, mais sçavez vous

De qui, et de quelle flame?

DE CHRIST son divin Epoux,

D’un sainct baizer de son Ame.

(f. Eiijv ${ }^{\circ}$ )

58

I.D.B.A.

Que ne peut l'amour de CHRIST?

A CHRIST toute dédiée

Elle s'estoit niée, affin

Que de CHRIST ne fust niée.

(f. $\mathrm{E}_{5} \mathrm{r}^{\circ}$ )

Pour une poésie sacrée: Michel de l'Hospital, Flaminio \& Denisot

Marguerite et les siens partagent donc cette «relligion» ou «inspiration evangelique», une religion où la vertu de l'amicitia, la caritas chré- 
tienne jouent un rôle fondamental. Les épitres ${ }^{\mathrm{IO2}}$ du chancelier à Marguerite sont des exemples de fraternité et de connivence, des éléments d'une communication qui ne veut pas être interrompue, un exercice d'écriture qui défie l'éloignement physique et le temps qui passe. ${ }^{\mathrm{I0}}$ Dans ce rapport d'amitié, la communion spirituelle semble presque annuler la profonde différence de statut social entre la princesse et son chancelier. Michel est pour elle «celuy que j'ayme, honore et estime comme mon pere et milieur ami», mais aussi un Te quasi me alterum, dans une dialectique amicale et rhétorique évoquant Cicéron / Atticus, Érasme / Saint-Jérôme, Montaigne / La Boétie ou Maistre Clément / Lyon Jamet. ${ }^{\mathrm{10}}$

Ils se réfugient ainsi dans un monde de livres, ${ }^{\text {Ios }}$ à l'abri des tempêtes du monde, tout en ne cessant de combattre, avec les instruments et le pouvoir qu'ils possèdent, pour que vertu et sagesse triomphent. «Attentif aux évolutions de la fortune»,, ${ }^{\mathrm{o} 6}$ comme ses amis de la première heure, comme Mile Perot ${ }^{107}$ et les autres padouans fascinés par Machiavel qui n'a pas encore les connotations noires et diaboliques qu'il va acquérir par la suite, ${ }^{108}$ et par sa dialectique fortuna / virtù, il ne veut pas «suivre [la première] systématiquement comme la fleur qui tourne perpétuellement avec le soleil» ${ }^{\mathrm{1} 9}$ mais, en choisissant la seconde, il veut garder sa fière indépendance, "suivre son chemin», soutenu par la conscience aiguë de sa vertu inébranlable et de sa foi en Christ:

je préférerai toujours le service de Dieu et les préceptes de la vertu; que m'importent les récompenses ou les promesses des hommes. Les biens dont le ciel comble ses élus valent mieux que les mines d'or ou les diamants de l'Arabie; c'est Jésus qui est le dispensateur des véritables récompenses promises à nos pères et à leur postérité. Bien fou qui préfère l'incertain au certain, le mensonge à la verité, et les quelques heures d'une jouissance passagère à l'éternelle félicité. ${ }^{\text {Io }}$

Or, Michel de l'Hospital dans ses magnifiques épitres à Marguerite, évoque et recommande entre autres à la princesse deux ouvrages. Le premier, publie en I550, est le recueil de Marcantonio Flaminio, le célèbre auteur du Beneficio di Cristo, livre emblème de l'évangélisme italien, et traducteur de Valdès, l'autre le Tombeau de Marguerite de Navarre que nous avons déjà évoqué.

Le recueil de Flaminio: 
M. ANTONII FLAMINII / DE REBUS DIVINIS / CARMINA, / AD / MARGARITAM HENRICI / Gallorum Regis Sororem./ LUTETIAE, / Ex officina Rob. Stephani typographi Regii. / M.D.L./ EX PRIVILEGIO REGIS.//. (ex. BnF Rés. Yc i 369)

réunit dans l'édition de Robert Estienne une gerbe de poèmes dans lesquels le disciple de Valdès et le fidèle ami de Vittoria Colonna "praedicat beneficia Christo in se et ceteros mortales collata», ce même «admirable benefice» que Le Fèvre d'Etaples avait évoqué partout dans ses Epistres et Evangiles pour les cinquante et deux semaines de l'an, s.l. n.d., [Paris, Simon du Bois, IS25]:

Il a porté noz pechés en son corps sur le bois. Et a baillé deux deniers satisfaisant pour nous. [...] Recongnoissons ces grans benefices de luy. $(52 \mathrm{~b})^{\mathrm{II} 2}$

Marguerite lit d'ailleurs la Bible de Le Fèvre. A Turin sont conservés un exemplaire $d u$ Nouveau testament de Le Fèvre d'Etaples (Bib. Antica, ASTO) et le seul exemplaire complet, avec l'ex-libris: «ce livre est à Marguerite de France» (fig. 4), de l'Ancien testament contenans les cinq livres de Moyse, Anvers, Martin Lempereur, I528. "I3 Marguerite possédait aussi dans sa Bibliothèque, à côté d'autres importants ouvrages manuscrits de poésie et de musique, un manuscrit $d u$ Miroir de Jhesus Christ crucifié (B.N. de Turin, Ms. $L V_{4}$ ) qu'elle avait apporté de France à l'occasion de son mariage. $^{\text {I } 4}$

Dans lépitre Ad Margaretam Valesiam. Franc. Regis Valesiam filiam. De sacris carminibus M. A. Flaminii (éd. I585, f. 67 / Poésies complètes, $p .75)$, "Is Michel de l'Hospital recommande à Marguerite le poète Flaminio qui, pour elle, a abandonné les muses profanes pour la lyre chrétienne ("lyram sacrumque ad sidera carmen»): "Omnia vim sentire tuam radiisque noveri, / Virgo tuis, tamquam solis fulgore videntur. / Haec quoque Flaminium insigni modo nomine vatem / Impulit, ut tandem nugis in morte relictis, / Aptaretque lyram sacrumque ad sidera carmen / Pangeret ac postrema tibi monumenta dicaret / Haec sua, regali donum regale puellae»,, "'6 une épître où le chancelier semble souligner avec force l'importance de ces poèmes sacrés offerts par le poète malade à Marguerite. Flaminio en effet, encouragé 


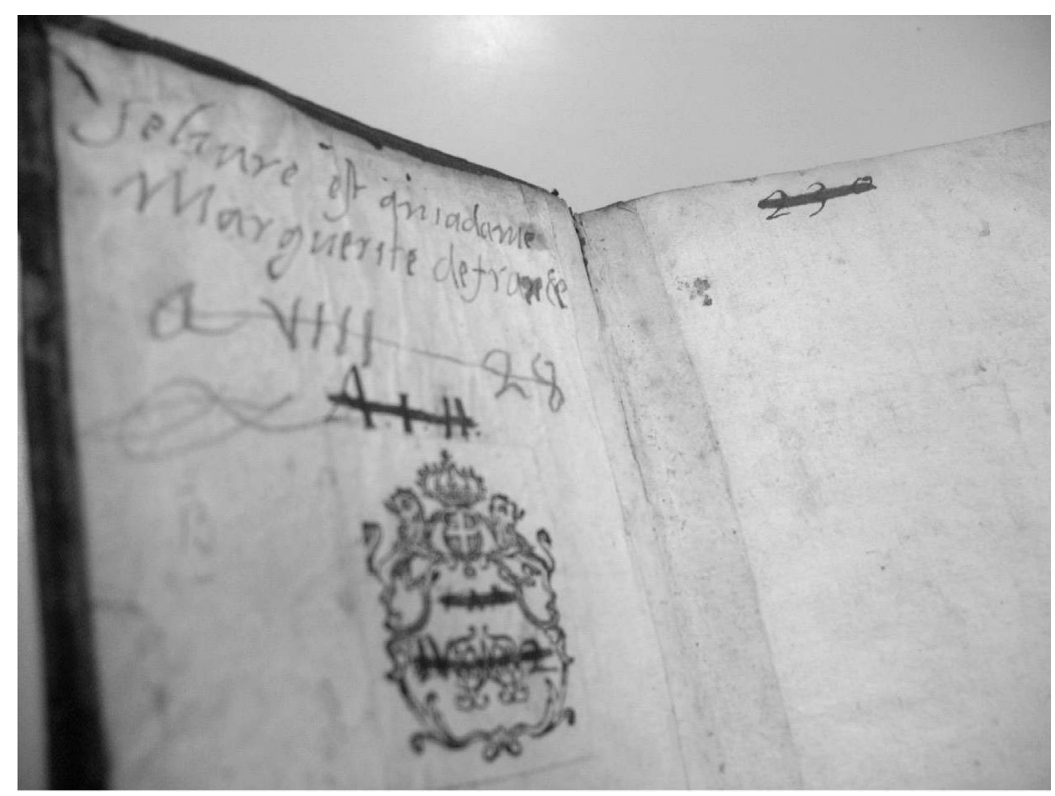

FIG. 4.

B.N. de Turin (cote: Ris. I9. I 2-I 5 )

par Pietro Carnesecchi, alors à Paris, offre son dernier ouvrage de Rime spirituali en latin, De rebus divinis carmina, publié à Paris en I550, chez Robert Estienne, à Marguerite (Margaritae Henrici Gallorum Sorori M. Antonius Flaminius). ${ }^{\mathrm{I}}$

Tout semble concourir dans ces années au développement, autour de Marguerite, d'une poésie sacrée déjà théorisée par Michel de l'Hospital dans son épître Ad Claudium Espensium nobilissimum et doctissimum Theologum, de poesi Christiana judicium, et exemplum (I 7), un texte que Loris Petris date de 1547-48 [Trente, Noël, I547] et qui est à la fois une théorie poétique évangélique et son illustration par un bymne de Noël, mystère de l'Incarnation qui, avec la Passion, est au cour de la foi chrétienne et oriente, ainsi qu'on le sait, le calendrier de l'Olive [Vittoria Colonna aussi a écrit deux poèmes sur Noël et de nombreux poèmes sur la mort du Christ, véritable obsession]. ${ }^{\text {I } 8}$ Une poésie sacrée donc, chère à la princesse qui, selon son chancelier (Epître Ad Pontronium, 26-28 / I585: 34-35), semble avoir abandonné ses auteurs bien-aimés: Virgile, Horace, Cicéron, pour les livres «saints». «Les-a-t-elle quittés dans ces temps sacrés pour 
se pénétrer des livres saints?», écrit L'Hospital, ce qui semblerait indiquer un revirement, dans ces années, une "conversion" à une littérature sacrée, connotée par le recentrement sur le Christ, la douceur évangélique et le don de la grâce. ${ }^{\text {II }}$ L'épittre I, 7 du chancelier est fondée, comme les poèmes et les auvres de Flaminio, sur un christocentrisme digne de Vittoria et de son entourage: le Christ «seul» peut ouvrir les yeux des hommes et faire cesser la nuit, enlever le ténébreux voile et inonder les cours de lumière, «et omnes / caelesti puras implevit lumine mentis» (vv. 237-38). Il insiste sur la douceur du Christ, il emprunte, comme Vittoria, la via dolce.

«Et morte soit tousjours pour moy la mort»: consoler Vittoria, consoler Marguerite

Claude d'Espence, qui partage la philosophia christiana de son ami "hic Christo, ac mibi vivo», écrit Olivier ${ }^{\mathrm{I} 2 \mathrm{O}}$ et sur lequel vient de paraître un important volume à la Maison d'Erasme, ${ }^{\mathrm{II}}$ offre d'ailleurs à Marguerite, le I ${ }^{\text {er }}$ mai I547, la traduction des Quatorze consolations pour les affligés et pour les travaillés (Tessaradecas consolatoria pro laborantibus et oneratis) de Luther ${ }^{\mathrm{I22}}$ pour la consoler de la mort de son père: ${ }^{123}$

j'ay institué une consolation spirituelle, laquelle je presente à V. S. comme une table, table non d'or, ou d'argent, mais table spirituelle, laquelle j'espere sera utile pour eriger et confirmer vostre Chrestien esprit. Icelle table est divisée en deux parties, la premiere contient sept ymages des maux, lesquelles considerées allegent les presentes calamitez: l'autre propose aussi sept ymages des biens amassez pour mesme usage. Prenne donc V. S. en gré mon tel quel labeur, et que tellement en use que par diligente leçon et d'icelles ymages, quelque peu se repose.

De vostre tresillustre seigneurie le tres humble et tresobeissant serviteur. C.D.

De la court. Le premier jour de May L'an I547.

Le texte de la Consolation en adversité ${ }^{124}$ fut condamné par la Sorbonne, le 3I aô̂t I553, avec la Paraphrase sur l'oraison dominicale; inséré dans l'Index de l'Université de Paris de 1557, il fut par 
la suite rayé de l'Index et il disparut de la liste des ouvrages interdits. Tout comme le Tombeau de Marguerite de Navarre, dédié à sa nièce et héritière de son message spirituel, la Consolation, teintée de néoplatonisme (la vie n'est qu'une prison), est fondée sur la certitude que la mort n'est pas la fin de notre vie, mais inaugure un nouveau «commencement de vie»):

O tresbonne mort qui nous delivre de telz perils, et totalement arrache de nous peché! [...] fin de peché, commencement de vie, et de justice. Parquoy qui ayme vie et justice, necessairement il ayme et n'ha en aucun horreur de la mort, comme la ministre et un ouvroir d'icelles.

(Consolation, ff. 9I-92)

L'exemple «tres clain» et «tant evident» $(f .4)$ à suivre est celui $d u$ Christ qui, "par le tresgrand amour envers le genre bumain est descendu du sein du pere en nostre prison et noz miseres, c'estadire en nostre chair, et trescalamiteuse vie, ha prins et porté en soy la peine deue à noz. pechez, à fin que nous fussions sauvez, selon qu'il dit: Tu m'as donné labeur par tes pechez, \& m'as fait travailler pour tes iniquitez?! (f. $A 2 v^{\circ}$ ).

Quand tu oys Jesuschrist le filz de Dieu avoir par son tressaint attouchement consacré toutes passions, santifié la mort, beneit malediction, glorifié deshonneur, enrichi povreté, tellement que la mort est contrainte d'estre la porte de vie, malediction la source de benediction, diffame mere de gloire, comment peux tu estre tant dur et ingrat, que tu n'ayme et souhaite toutes passions, comme teintes, santifiés, benite par la tressainte chair et le trespur sang de Jesuchrist?

(Consolation, ff. 62-63)

La consolation opère donc, comme les poèmes christocentriques de Flaminio et de Vittoria Colonna, un recentrement sur la figure du Christ, et sur la «foy vive», syntagme cher au langage de la tribou évangélique. ${ }^{\mathrm{I} 25}$ Cette expression revient trois fois dans les dernières pages de la Consolation (deux fois $f$. I3) et f. I38 «vive foy»):

Le chrestien pourveu que de foy vive [...], se peult glorifier de tous les merites et biens de Christ, ne plus ne moins que s'il les avoit faitz en personne, tant luy sont faitz propres, tellement que ja peult tout asseuré 
attendre le jugement de Dieu; jugement toutesfois qu'on ne peult soustenir, si grande chose est ceste foy vive, tant de biens nous fait elle, tant nous rend elle glorieux filz de Dieu.

(Consolation, f. I 35)

D'Espence, qui écrit à l'ombre de Saint Paul, très souvent évoqué dans les notes en marge du texte, mais aussi du paratexte, «enseigne» à la princesse en deuil comment «cercher reconfort» car si «nous devions ceste bumanité à tous desolez de les consoler, toutesfois nous en sommes principalement redevables envers les fideles car $S$. Paul fait manifeste difference entre les estrangers et domestiques》 (f. $\sigma$ ). Principale source de reconfort et de consolation, "les escritures». ${ }^{{ }^{2} 6} \mathrm{La}$ Consolation reprend fidèlement toute la structure du texte luthérien: sept images qui représentent le mal, sept le bien et la fin de l'évocation aboutit au Christ:

Quand tu oys Jesuschrist le filz de Dieu avoir par son tressaint attouchement consacré toutes passions, santifié la mort, beneit malediction, glorifié deshonneur enrichi povreté, tellement que la mort est contrainte d'estre la porte de vie, malediction la source de benediction, diffame mere de gloire, comment peux tu estre tant dur et ingrat, que tu n'ayme et souhaite toutes passions, comme teintes, santifiés, beeite par la tressainte chair et le trespur sang de Jesuchrist?

(Consolation, ff. 62-63) ${ }^{\mathrm{I} 27}$

Exemple magnifique de cette conversation évangélique, avant la Consolation, avant le s. IIo, Vittoria, qui avait écrit «per morte l'uom si fa immortale», ajoutait:

$$
\begin{aligned}
& \text { convien ch'a morte il gran nome si toglia. } \\
& \text { La pura fe', l'ardor, l'intensa pena } \\
& \text { mi scusi appo ciascun; ché 'l grave pianto } \\
& \text { è tal che tempo né ragion l'affrena. }{ }^{128}
\end{aligned}
$$

Le thème de la consolation est d'ailleurs récurrent dans les lettres de Vittoria et le verbe «consoler» revient deux fois dans la gerbe finale de l'Olive. ${ }^{\mathrm{I}}{ }^{29}$ Christ est le «unico consolatore degli afflitti». La confiance de Vittoria Colonna en l'abandon au «bénéfice du Christ» est, comme 
pour Flaminio, absolue. Christ est le seul livre - «il libro de la croce»où il se montre «vivo», comme dans le dessin de Michelangelo:

$$
165
$$

Doi modi abbiam da veder l'alte e care grazie del Ciel: l'uno è guardando spesso le sacre carte ov'è quel Lume expresso ch'a l'occhio vivo sì lucente appare;

l'altro è alzando del cor le luci chiare al libro de la croce, ov'Egli stesso si mostra a noi sì vivo e sì da presso che l'alma allor non può per l'occhio errare.

Con quella scorta ella se 'n va sospesa, sì che se giunge al desiato fine passa per lungo e dubbioso sentero; ma con questa sovente, da divine luci illustrata e di bel foco accesa, corre certa e veloce al segno vero. ${ }^{\mathrm{I} 28}$

Un Luther donc pour Marguerite, comme Rinaldo Corso avait traduit un Luther pour les dames de Correggio ... étranges cö̈ncidences. Pourquoi Marcantonio Flaminio, qui n'hésitait pas à parler dans ses lettres du «stupendo misterio» de la prédestination («El passa troppo», disaient ses confrères), ${ }^{1}{ }^{\mathrm{I}}$ offre-t-il sa dernière gerbe poétique où domine la poésie du Christ à Marguerite? Nous trouvons peut-être une réponse à cette question et au «cangiato stile», à ce revirement, même lexical évidemment, dans les Costituti de Pietro Carnesecchi ${ }^{32}$ où sont nommés, comme 〈pro haereticis vel de haeresi suspectis viventes et mortuos»: Flaminio, Pole, Priuli, Morone, di Capua et notre Vittoria Colonna. Carnesecchi, qui vivait alors à la Cour de France et qui est le trait d'union entre Flaminio et Marguerite, révèle dans son V Costituto, daté du I3 juillet I566 (il sera brûlé l'année suivante), que non seulement il avait parlé plusieurs fois avec Madame Marguerite «in laude del Flaminio», un auteur dont elle appréciait les travaux sur les psaumes (une édition avait été publiée chez Estienne en I546), ${ }^{133}$ mais que:

Trovai ch'ella teneva la iustificazione per la fede come teneva io in quel tempo e $[. .],.{ }^{134}$ havendoli mostrato alcuni scritti del Flaminio che non mi ricordo quali fussero, mostrò che li piacessero assai.

(Costituti Carnesecchi, f. 89v) 
Et dans l'une de ses lettres, lui qui avait écrit des lettres importantes sur la justification par la foi, ${ }^{\mathrm{I}}{ }^{3}$ il ajoute que la princesse:

era dotata di quella charità, humiltà et mansuetudine che si rechiedeva a una excellente christiana et che fusse regenerata per lo spirito di Dio, cioè che avesse racquistato mediante la gratia del medesimo Dio quella divina imagine secondo la quale siamo simili a Dio. [...] È ben vero che io presupponevo che la signora donna Giulia [Gonzaga] ${ }^{136}$ et lei dovessino convenire insieme ancor quanto alle cose della religione, havendo io per opinione che la prefata madama Margherita non dissentisse ne l'articolo della giustificatione per la fede da quel modo che lo teneva la signora donna Giulia [Gonzaga].

(ff. 237-39, cf. aussi ff. 730-3 I I)

Le «cangiato stile» de du Bellay, le nouveau lexique de I5so s'inspirait-il donc à ces débats qui avaient lieu à la Cour de Marguerite, une cour où l'on parlait de Dieu, comme Jodelle le révélera un peu plus tard? $?^{138}$

«Esser io niente et in Christo trovar ogni cosa»: Vittoria et la justification par la foi

Un principe, celui de la justification par la foi, qui sous-tend plusieurs poèmes de Vittoria comme les sonnets 59 et I2 des Rime spirituali. ${ }^{3}{ }^{39}$ Vittoria qui écrit, dans le sonnet I57, que Dieu la rend juste, justa facere, c'est-à-dire le but de la justice du Christ est celui de rendre juste le pécheur, mais une justice que l'on obtient «solo per fede» (sola fide):

Divino spirto, il cui soave ardore ne infiamma, e col gran Padre in dolce modo, per mezzo del Signor nostro, ad un nodo lega l'alme ben nate in vero amore,

tante grazie e non più pò darti il core quanto lume riceve, e quel sol lodo che, tua mercede, intendo, e mentre godo del foco sacro tuo ti rendo onore. 
Io per me sono un'ombra indegna e vile, sol per virtù de l'alme piaghe sante del mio Signor, non per mio merto viva;

Egli giusta mi rende, sciolta e priva del vecchio Adamo, e tu, mio caro amante, rendimi ognor più accesa, ognor più umile. ${ }^{\mathrm{I} 40}$

Car «Dieu a souffert pour demonstrer sa justice en ce temps icy: affin qu'il soit juste et justifiant celuy qui est de la foy de Jesuschrist», comme Le Fèvre l'écrit en I523 - et c'est la Bible que lit Marguerite et qu'elle a apportée avec elle à Turin [cf. aussi Olivétan: "Dieu a supportezpour demonstrer sa justice au temps de maintenant: affin qu'il soit juste et justifiant celuy qui est par la foy de Jesus»], car écrira Du Bellay, dans sa lecture du sonnet de Veronica Gambara, autre «scur en vérité» de Vittoria, "le Juste seul ses esleuzjustifie» (s. II2, v. 9), ce qui équivant, comme Campi le dit pour le sonnet de Veronica, Divino spirto, il cui soave ardore, à «mettere la scure alla radice di ogni fraintendimento meritorio delle opere umane, annullare il principio del merito». ${ }^{\text {I4I Si les }}$ poèmes de Vittoria reflètent donc les positions théologiques des «frères en vérité» de l'ecclesia viterbensis et impliquent "l'accettazione della dottrina della giustificazione imputativa che esclude ogni merito umano», " ${ }^{42}$ Carnesecchi parle de "quel benedetto articolo della giustificazione» qui était au centre des sermons d'Ochino. ${ }^{\text {I3 }}$ Veronica Gambara n'est pas loin des positions théologiques du sonnet Padre eterno del Ciel, se, Tua, mercede, ò̀ Vittoria développe la parabole évangélique de la «vite e $i$ tralci»» «le vrai cep» (Jean, Is):

Padre eterno del Ciel, se, Tua mercede, vivo ramo son io ne l'ampia e vera Vite ch'abbraccia il mondo e Seco intera vuol la nostra virtù solo per fede,

l'occhio divino Tuo languir mi vede per l'ombra intorno a le mie frondi nera s'a la soave eterna primavera il quasi secco umor verde non riede. Purgami sì ch'io rimanendo Teco mi cibi ognor de la rugiada santa 
e rinfreschi col pianto la radice.

Verità sei; dicesti d'esser meco;

vien dunque omai, sì ch'io frutto felice

faccia in Te degno di sì cara Pianta. ${ }^{\text {I4 }}$

La justice qui nous parvient des plaies du Christ revient comme un fil rouge dans les Rime de Vittoria qui écrit, dans une lettre de I542: «Et Dio volse che [...] mi si mostrasse esser io niente et in Christo trovar ogni cosa» (lettre de Viterbo, le 22 décembreI542). Le mot «fede» revient comme un refrain, véritable obsession lexicale dans les Rime de Vittoria, inondées de: «viva fede» [ «foy vive», le même «syntagme évangélique» de la Consolation], «candida fede», «vestiti sol di pura fede viva», "pura ardente fede», "sovra natural divina fede», "vera e umil fede», "viva grazia»", "sol di fede armato», "la mia salda e pura fede»; ${ }^{\mathrm{I} 5}$ une obsession lexicale qui teinte d'une lumière différente les nombreuses récurrences du mot "foi" de l'Olive et dont les résonances ou connivences évangéliques ont déjà été justement mises en relief. ${ }^{\mathrm{I}}{ }^{\mathrm{G}} \mathrm{Le}$ mot «foy» y est souvent accompagné du possessif «ma» ou d'épithètes comme «ferme», «nette, et franche» ou encore «antique» (que l'on retrouve chez Colonna, «antica fede» dans le s. 45) ${ }^{\mathrm{I}}{ }^{7}$ dans ce recueil où affinités et thèmes évangéliques résonnent sans cesse.

45

Amor, tu sai che già mai torsi il piede dal carcer tuo soave, né disciolsi dal dolce giogo il collo, né ti tolsi quanto dal primo dì l'alma ti diede; tempo non cangiò mai l'antica fede; il nodo è stretto ancor com'io l'avolsi; né per il frutto amar ch'ognor ne colsi l'alta cagion men cara al cor mi riede.

Vist'hai quanto in un petto fido e ardente può oprar quel caro tuo più acuto dardo, contra del cui poter Morte non valse.

Fa' omai da te che 'l nodo si rallente, ch'a me di libertà già mai non calse; anzi, di ricovrarla or mi par tardo

Une foi illumine le cour de Vittoria qui se fait transparent comme le «cuore de cristallo» de Bembo ${ }^{18}$ et émaille de «chiaroscuri» les 
Rime de Vittoria, les inonde des lumières et des ombres de son parcours de renouvellement et d'«illuminazione interiore» (Firpo a mis en évidence la matrice alumbrada de certains termes lexicaux) et fait voir des «lumieres et une flamme incongnues» («Toy, qui fis voir la lumiere incongnue», s. 90 v. I). Ces effets de lumière éclairent et obscurcissent en même temps les vers de l'Olive, comme les magnifiques vers: «L'obscur m'est cler, et la lumiere obscure» (s. 26 v. 8), "Cler à luy seul, à tout autre obscurci» (s. 88 v. 8), "Daigne eclersir l'obscur de vostre voile» $\left(\begin{array}{llll}\text { s. } 6 I & \text { v. IO }) .{ }^{\mathrm{I}} 49\end{array}\right.$

«La predestinatione assolutamente»: Veronica Gambara «è con loro»

Vittoria qui possédait une autorisation à lire les livres hérétiques ("licentia di leggere libri probibiti») partage les idées de ses «frères en vérité» et Carnesecchi, avec qui elle parlait de «cose spirituali», le confirme: «mi pare avere compreso leggendo qualche suo sonetto, che ella tenesse la predestinatione assolutamente, a non so dire a ponto in che modo». ${ }^{150}$ À la lumière de toutes ces considérations, le choix de Du Bellay d'imiter le sonnet de la prédestination, Scelse da tutta la futura gente, de Veronica Gambara semble acquérir de nouvelles implications. ${ }^{15 \mathrm{I}}$ Peut-on traduire, imiter, pour faire plaisir à quelqu'un ou sous l'influence de quelqu'un? Peut-on s'intéresser à un milieu qui nous est familier grâce aux liens que «Madame» (ce terme revient plusieurs fois) entretient avec des poètes qui ont passé les monts et qu'elle a accueillis avec son habituelle générosité?

Pourquoi donc Veronica Gambara? Sans doute Du Bellay qui lisait la table des incipit des Rime di diversi autori comme un magnifique réservoir de vers a (ce que Millet a bien mis en évidence pour les Rvf dans son bel essai sur Du Bellay et Pétrarque), ${ }^{\mathrm{I}} 2$ aurait pu être frappé esthétiquement par ce Scelse da tutta la futura gente, par sa rime et ses accents. ${ }^{15} 3$ Tout est possible, probable, notre attention souvent tombe sur des détails, sur des madeleines poétiques qui nous font penser à nos mystères, à nos goûts secrets, à ce goût dolce amaro qui marque notre vie... Mais est-ce que Du Bellay n'est pas allé lire ce sonnet, frappé, non tant pour son incipit, mais tout simplement parce qu'il connaissait le nom de Veronica Gambara. Comment ne pouvait-il pas connaître ce 
nom, lui qui connaissait l'Orlando furioso à la perfection et l'exploitait comme un magnifique réservoir de rêves d'amour et de douleur? ${ }^{\mathrm{I}} 4$ Le poète ferrarais n'évoque-t-il pas Veronica, lors de l'arrivée au port de sa magnifique nef poétique et romanesque, parmi les dames qui accourent en fête?

O che belle e saggie donne veggio,

o di che cavalieri il lito adorno! ...

Mamma e Ginevra e l'altre da Correggio ${ }^{\text {is } 5}$

Veggo dal molo in su l'estremo corno;

Veronica Gambara è con loro

Sì grata a Febo e al santo Aonio coro.

(Orlando furioso, XLVI 3)

Ces vers ne pouvaient-ils pas suffire pour susciter l'intérêt de Du Bellay et de sa Minerve qui, dès ces années, bien avant Turin, bien avant Grévin et tant d'autres «frères et scurs exilés》, ${ }^{156}$ protège des gens comme Pietro Carnesecchi (brûlé en I567), accepte les dédicaces poétiques de Marc'Antonio Flaminio le rédacteur du Beneficio di Cristo, publié à Venise en I543?

Du Bellay ne s'inspire-t-il pas, sonnet après sonnet, de l'anthologie des Rime diverse di molti eccellentissimi autori, le premier livre de I545, paru chez Giolito et dirigé, voire orchestré de façon collective, par un team Betussi-Domenichi? ${ }^{157}$ Ce même Lodovico Domenichi ne put se sauver du bûcher que grâce à l'intervention directe de Renée de France; Giuseppe Betussi, par contre, dans sa traduction de Boccace, Il libro delle Donne Illustri, ${ }^{158}$ n’hésite pas à insérer Marguerite de Navarre en compagnie de Renée de France et de Vittoria Colonna et naturellement Veronica Gambara (f. 197), dans une galerie de femmes de son siècle qui suivent «lo spirito di Paolo» et «amano l'Evangelio». A Margherita di Valesia, ${ }^{159}$ Betussi consacre un portrait saisissant, peut-être inspiré par l'éloge de Vergerio, évoquant toute l'admiration que ces milieux bétérodoxes éprouvaient pour Marguerite, pour sa Vie, entre Marthe et Marie. ${ }^{160}$ Comment ne pas penser aux tentations bérétiques de Betussi en lisant ce "cammeo", cet éloge sans réserve de cette femme dont "l'intelletto molto elevato, et molto pieno di carità et molto acceso di Christo», écrit P. P. Vergerio, ${ }^{16 \mathrm{I}}$ avait frappé et encouragé "les frères en vérité», comme Renée, et incarné l'espoir de tant d'hommes et femmes en une renovatio profonde de l'Eglise? ${ }^{162}$ 
«Nel core degli eletti», la «dolce dottrina di libertà e predestinazione»

Mais revenons à l'Arioste - objet dans l'Olive «de prestiti sconcertanti), ${ }^{1{ }_{3}}$ parce qu'imiter Bembo n'est pas imiter l'Orlando (mais là il faudrait prendre en compte la lecture fragmentée que les Français font de l'Arioste) - l'un de ces hommes aux dangereuses et courageuses inclinations pour une réforme radicale de l'église corrompue ${ }^{\mathrm{I} 4}$ qui dominent le milieu scientifique, académique et culturel de la ville des Este; l'un de ces hommes capables de greffer leur savoir d'un domaine à l'autre, apparemment renfermés dans leur hortus conclusus ou leur tour d'ivoire, en réalité tissant des fils rouges entre science, religion, politique et culture et créant des réseaux de relations, en France notamment, à Lyon et ailleurs, en Allemagne, aux Pays-Bas... Des hommes qui par leur présence et leur cuvre ont donné à la Renaissance ferraraise cet aspect inquiet et irrégulier qui la connote. ${ }^{165}$ Un auteur, Lodovico Ariosto, censuré à plusieurs reprises, et qui fait prononcer à Charlemagne une prière qui n'a pas besoin de commentaire:

So che i meriti nostri atti non sono

a satisfare al debito d'un'oncia; né devemo sperar da te perdono, se riguardiamo a nostra vita sconcia: ma se vi aggiungni di tua grazia il dono, nostra ragion fia ragguagliata e concia.

(Orlando furioso, XIV 72)

L'Arioste se fit d'ailleurs enterrer dans le couvent des bénédictins de San Benedetto impliqués dans l'affaire $d u$ Beneficio di Cristo, livre emblème de la Réforme italienne, ${ }^{\mathrm{I} 66}$ un livre que Jean de Tournes publie à Lyon en I545 dans la traduction de Claude Le Maistre Lyonnais: Du benefice de Jesus Christ crucifié envers les chrestiens, traduict de vulgaire italiens en françois. Le seul exemplaire connu de cette traduction, censuré en I547, a été détruit (Cartier, De Tournes I, n. 4I), mais, récemment, Guillaume Gerthon a retrouvé un exemplaire du Benefice en Allemagne. ${ }^{167}$ N'oublions pas que Du Bellay traduit presque sans variantes les tercets de Veronica où le thème christique, paulinien triomphe: 
Chiamando gli fa giusti, e giusti poi

Gli essalta sì, ch'a l'unico suo figlio

Gli fa conformi, e poco men ch'eguali.

Qual dunque potrà mai danno o periglio

Ne l'ultimo de gl'altri estremi mali

Da Christo separar gli eletti suoi?

Un sonnet, celui de Veronica, qui sera publié, en I548, avec quelques variantes («predestinando» devient «predestinati») qui approfondissent l'engagement évangélique de sa pensée, mais qui concentre bien dans sa forme les aspirations, les tendances hétérodoxes d'un monde en plein ferment qui à Correggio trouve l'un de ses centres esleus. Un centre savant et raffiné, di belle donne e saggie, mais où Rinaldo Corso, le poète de cette cour, dédie à suor Barbara, alias Isotta da Correggio, la Prefatione nella Pistola di san Paolo a' Romani, une traduction de Luther, publiée à Venise par Comin da Trino en I545, qui est un "concentrato purissimo di teologia luterana, nel quale lo stato di legge et lo stato di grazia, la giustizia delle opere e la giustizia della fede vengono contrapposti in un'alternativa frontale, priva di sfumature». ${ }^{\mathrm{I} 68}$ Correggio où on lit les Dialoghi d'amore de Léon Hébreu, on lit Luther, on accueille des savants et des poètes, de l'Arétin, qui adore les pêches de ce «paradisetto terrestre», à Ortensio Lando, qui définit Veronica «donna rara, et di honor amica», de Bembo à Bernardo Tasso, de Molza à tant d'autres esprits ouverts aux nouvelles idées. ${ }^{169}$

«Suyvez des cerfs la trace fugitive»: du Beneficio di Christo au De rebus divinis carmina

Si nous savons ${ }^{170}$ que la version définitive $d u$ Beneficio di Cristo et les ajouts calvinistes sont dus à Marcantonio Flaminio, membre du cercle de Bembo à Padoue et de celui de l'évêque Giberti à Vérone et, plus tard, de celui de Valdès à Naples, dont il était le disciple esleu («Allevo» qui «più di ogni altro l'amava ed ammirava»), ${ }^{17 \mathrm{I}}$ ce poète du Christ mérite toute notre attention, ainsi que nous l'avons déjà souligné. ${ }^{172}$ Flaminio écrit, dans l'une de ses lettres passionnées: «A salvarsi basta la fede, non bisogna operare, però che l'opere non giustificano, ma solamente la fede senza l'opera giustifica», ${ }^{173}$ "ssenza particolare gratia et aiuto de Dio lo huomo non se astiene di mettere oppositione» au 
"superceleste lume con cui Dio chiama la salvezza», et il ajoute «tutte le cose che ci conducono alla vita etterna sono effetti della predestinazione». ${ }^{174}$ Il prêchait d'ailleurs, devant le cardinal Pole: «apertissimamente che solo per lo sangue di Giesù Cristo havevamo la remission de peccati et vita eterna et non per le opere nostre, né il cardinale né niun altro ci replico mai in contrario: in modo ch'io tengo per certo che Sua Signoria reverendissima tenga la giustificazione secondo il libretto Del beneficio di Christo». ${ }^{175}$ Flaminio non seulement traduit et publie les ouvrages de son maître Valdès, mais il écrit des ouvrages comme les Meditationi et orationi formate sopra l'epistola di san Paolo a Romani, dédiées à une autre femme «spirituale», Giulia Gonzaga, et où l'on voit triompher son «unico alato maestro [...] Sancto Paolo». ${ }^{176}$ Il ne fait que souligner partout la centralité de la foi qui, écrit-il, «piantata» par son esprit «nel core degli eletti, cresce ognhora e produce frutti dolcissimi di carità». ${ }^{177}$

Or, ce poète (mis à l'Index en I559), ${ }^{178}$ entre eros et agapé qui présente plusieurs affinités avec Marot, emblème de la complexité et des différences des milieux bétérodoxes italiens qu'il a traversés l'un après l'autre, d'une ville l'autre, de Vérone à Venise, de Naples à Viterbe ... dans sa vie inquiète et vagabonde, publie en I546, sa Paraphrasis in xxx Psalmos versibus scripta, ${ }^{179}$ un ouvrage particulièrement apprécié par Marguerite de France qui pouvait le lire, dès I546, dans l'édition fournie par l'imprimeur à la marque de l'olivier, Robert Estienne, ${ }^{180}$ des Psalmi triginta, Latine cum poetica paraphrasis latina M. Antonii Flaminii, ${ }^{18 \mathrm{I}}$ et qui fit mettre en musique plusieurs psaumes. ${ }^{182}$ L'ouvrage est évoqué par Michel de l'Hospital, dans une épitre où le chancelier souligne l'importance de ce «parvum libellum, sed pium», de ces poèmes du Christ dédiés à la scur du roi. ${ }^{{ }^{183}}$ L'édition de I550 présente un important paratexte, une dédicace qui est une sorte de conversion à la poésie du Christ et deux poèmes, l'un à Pietro Carnesecchi (ad Petrum Carnesecum de Margarita Henrici Gallorum Regis Sorore M. Antonium Flamini, f. 34) qui fréquente le cercle de Marguerite, et l'autre à la Princesse qui, «caelestis ardens ignibus Amoris», est très sensible à la vie du Christ. En effet, un autre poète néo-latin, Salmon Macrin, qui faisait partie de l'entourage de Marguerite et dont les vers seront publiés avec ceux de Flaminio dans le recueil d'Henri Estienne de I556, envoie, en I549, à la princesse un abrégé de la vie de Jésus: Salmonij Macrini Iuliodunensis, 
Cubicularij regij, Epitome Vitae Domini nostri Iesu Christi, Ad Margaritam Valesiam, ${ }^{184}$ un ouvrage précédé d'un poème Ad Margaritam Valesiam, Henrici secundi Christianissimi Galliarum Regis sororem unicam sur lequel rayonne la lumière des Évangiles ("Clara Evangeliis spargere luce sui», f. a.ii.).

Ces poèmes représentent pour le poète «luterano et che insegnava sottomano le cose lutherane» ${ }^{185}$ et qui a failli mourir comme son ami Carnesecchi («se non fosse morto sarebbe bruciato», selon Pole), une sorte de testament spirituel, une profession de foi ultime où résonnent les thèmes $d u$ Beneficio di Cristo: l'imitation du Christ, ${ }^{186}$ le service d'amour du Chrétien, où, encore une fois, le lecteur averti peut «interpretare quei versi come una lunga divagazione intorno al tema centrale del Beneficio di Cristo». ${ }^{187}$ Le poème PRAEDICAT BENEFICIA a Christo in se et caeteros mortales collata $(f$. I3) reprend le titre même de ce livre-emblème de la Réforme italienne et tout le recueil réaffirme, avec conviction, le rôle central du Christ, sa suprématie, sa préeminence absolue sur tout: «Tu quies / Lumine, voluptas mentium». La religion donc, comme amour, comme abandon confiant au Christ qui, par son sacrifice, a sauvé l'homme, l'a amené vers le bonheur céleste. Le recueil du cygne mourant prend et fait prendre à l'auteur tresdevoué $^{188}$ un chemin nouveau, celui de l'amour et de l'abandon au Christ. Est-ce le «sentier inconnu» (s. I) que «l'aele inusitée» du poète suit dans son parcours ascendant vers les "celestes beautez»? La foi comme grâce, et la grâce comme don qui parvient à l'homme non par ses mérites, par ses bonnes cuvres, mais par la grâce de Dieu, par sa surabondance divine est un des thèmes-clés de ce magnifique recueil émaillé de la lumière des étoiles, bercé par le bruit de la mer et protégé par les arbres pâles et amers. La réponse de l'bomme est dans sa vie restituée par l'amour, dans une renovatio qui passe à travers l'union avec Dieu. La réaffirmation de la suprématie du Christ sur tout instant, sur toute forme et force de la vie religieuse, ce christocentrisme absolu des poèmes publiés, en I550, en l'bonneur de MinerveMarguerite, ces de rebus divinis carmina, peuvent donc éclairer d'une nouvelle lumière les branches de l'Olive qui, dans la gerbe finale, entressent leurs rameaux sacrés pour devenir la croix du fils de Dieu.

Rosanna Gorris Camos 
i. Cf. Vittoria Colonna, «Rami d'un arbor santo e una radice», Rime amorose disperse in Rime, éd. Alan Bullock, Bari, Laterza, 1982, p. 64 (sauf indication contraire nos citations des Rime renvoient à cette édition). Nous avons consulté plusieurs éditions des Rime à la Bibliothèque Civica de Vérone, à la B.N. de Turin et à Paris. Les allusions à l'olivier sont nombreuses: «precieux arbre», s. 62, I; «les sainctz rameaux de ma plante divine», s. 6I, 2; «heureuse branche de l'arbre sainct» S. 72, I-8; «sacrez rameaulx», S. 4, I 2; «rameaux d'une divine plante», s. 85,3 ; «son arbre», s. 91, I 2; «arbre sainct», 98, I-2, s. (imité de Claudio Tolomei qui parle pourtant de «ornate fronde»); «sainctz rameaux», s. IO3, I-2; «branche nouvelle», s. 104, 6; «au tige heureux», s. 105, I4. C. Tolomei, qui loue à plusieurs reprises Marguerite, écrit, en I 5 2, des sonnets pour Marguerite dans son Oratione de M. Claudio Tolommei, ambasciatore di Siena: recitata dinanæi al christianissimo re di Francia, Henrico II. A Compiegna il meze di Decembre, Iss2. Insieme alcuni sonetti fatti dal medesimo, in laude de l'illustrissima Madama Margherita di Francia, in Lyone, per Philiberto Roletto, I 553 . Sur ses rapports avec Marguerite, qu'il associe à Catherine de Médicis, «due rarissime e virtuosissime signore; e quasi i due occhi non pur della Francia, ma di tutta Europa», voir: A. Magalhaes, All'ombra dell'eresia, Bernardo Tasso e le donne della Riforma tra Italia e Francia, in Le Donne della Bibbia, la Bibbia delle donne, Rosanna Gorris Camos éd., Fasano, Schena, 201 2, pp. I 5 8-2 I 8.

2. G. Gorni, I tempi dell'Olive, «Italique», VI (2003), p. 79. Du Bellay aussi écrit: «Vrayment je confesse avoir imité Petrarque, et non luy seulement, mais aussi l'Arioste, et d'autres modernes italiens. Pource qu'en l'Argument que je traicte, je n'en ay point trouvé de meilleurs».

3. Gorni, I tempi dell'Olive cit., p. 8 I.

4. Sur les Fiamme de Giraldi, voir C. Molinari, Il canzoniere di un «intellettuale organico» alla corte di Ercole II d'Este: «Le Fiamme» di G. B. Giraldi Cinzio, in «Schifanoia», nn. 28-29 (2005), pp. 279-90 et R. Fedi, Canzonieri perduti, nascosti, dimenticati. Le Fiamme di G.B. Giraldi Cinzio, in La memoria della poesia. Canzonieri, lirici e libri di rime nel Rinascimento, Rome, Salerno, I990, pp. 3 1 3-26. Sur Giraldi, qui séjourna à Turin, voir R. Gorris Camos, "Jean Baptiste Gyraldi Cynthien Gentilhomme Ferrarois": il Cinthio in Francia, in Giovan Battista Giraldi Cinzio gentiluomo ferrarese, Atti del Convegno di Ferrara, I-2 dicembre 2004, a cura di Paolo Cherchi, Micaela Rinaldi, Mariangela Tempera, Firenze, Olschki, 2008, pp. 77-I 29.

5. Libro primo delle Rime, Venise, Giolito, i 545. Il existe une édition récente du recueil de Giolito: Rime diverse di molti eccellentissimi autori (Giolito I545), F. Tomasi et P. Zaja édd., San Mauro Torinese, Ed. Res, 200I. Sur ces anthologies, cf. A. Nuovo, C. Coppens, I Libri di rime: serialità e concorrenza, in I Giolito e la stampa nell'Italia del XVI secolo, Genève, Droz, 2005, p. i io sq.; F. Tomasi, Alcuni aspetti delle antologie liriche del secondo Cinquecento, in "I più vaghi e i più soavi fiori". Studi sulle antologie di lirica del Cinquecento, M. Bianco et E. Strada, Alessandria, Ed. dell'Orso, 200 I, pp. 77-I I I. Ronsard a annoté un volume réunissant la réédition de I $546 \mathrm{du}$ Libro primo et la réédition de $\mathrm{I} 548 \mathrm{du}$ Libro secondo, $\mathrm{cf}$. R. Lebègue, Un volume en vers italiens annotés par Ronsard, «Bulletin du Bibliophile», I95 I, pp. 273-80. Du Bellay travailla sur le Libro primo, cf. Joan Della Neva, Variations in a minor Key: Du Bellay's Imitations of Giolito Anthology Poets, «French Forum», I4/2 (1989), pp. I33-46. 
6. Cf. Le Tasse et l'Arioste en France, «Cahiers Saulnier», n. 20, Paris, PENS, 2003 , 304 et notamment l'article de K. W. Hempfer, Traditions discursives et réception partielle: Le Roland furieux de l'Arioste dans L'Olive de Du Bellay, pp. 53-74. Gorni aussi souligne l'importance de l'intertexte de l'Arioste, objet, selon lui, «di prestiti sconcertanti», cf. Gorni, I tempi dell'Olive cit., p. 38. Du Bellay l'imite dans au moins I 5 sonnets. Sur les affinités spirituelles entre l'Arioste et l'entourage de Veronica Gambara, voir R. Gorris Camos, Sul II2 dell'Olive, in European Petrarchism. Reading and Writing Petrarch in the Renaissance/Petrarchismo europeo. Leggere e scrivere Petrarca nel Rinascimento, Annual Meeting of Renaissance Society of America, Venise, 8-10 avril 2010, et Ead. Sous le signe de Pallas: paroles ailées et ascension de l'esprit dans l'Olive, in L'Olive de J. Du Bellay, Actes des Séminaires d'analyse textuelle Pasquali (Lucelle, les $\mathrm{I}^{\mathrm{er}}-4$ décembre 2005), Bologne, CLUEB 2007, pp. $167-232$.

7. Sur Bembo et ses Asolani, voir le beau livre de L. Bolzoni, Il cuore di cristallo. Ragionamenti d'amore, poesia e ritratto nel Rinascimento, Turin, Einaudi, 2010. Voir aussi pour ses liens avec le monde de l'évangélisme italien et avec Colonna: P. Simoncelli, Pietro Bembo e l'evangelismo italiano, in «Critica storica», XV (1978), pp. I-63; C. Dionisotti, Appunti sul Bembo e su Vittoria Colonna, in Miscellanea Augusto Campana, I, Antenore, Padova, I98 I, pp. 275-86; G. Fragnito, Intorno alla «religione» dell'Ariosto: $i$ dubbi del Bembo e le credenze ereticali del fratello Galasso, in «Lettere italiane», XLIV (1992), pp. 208-39; L. Pertile, Apollonio Merenda, segretario del Bembo, e ventidue lettere di Trifone Gabriele, in «Studi e Problemi di Critica testuale», XXXIV (1987), pp. 9-48; G. Moro, A proposito di antologie epistolari cinquecentesche (precisazioni su B. Pino e i Manuzio, T. Gabriele, A. Merenda e P. Bembo), in «Studi e Problemi di Critica testuale», XXXVIII (I 989), pp. 7I-99.

8. Tous ces auteurs italiens sont en rapport avec Marguerite et lui offrent des ouvrages, cf. R. Gorris Camos, La Bibliothèque de la duchesse: de la bibliothèque en feu de Renée de France à la bibliothèque éclatée de Marguerite de France, duchesse de Savoie, in Mélanges Barbier-Mueller, Genève, Droz, 20 I I, pp. 473-525 et, pour Bandello, Ead. "Questi bei fior e pallide viole»: Bandello et les poètes italiens de la bibliothèque de Marguerite de France, duchesse de Savoie, in "Parce que c'estoit luy...». Giornata di Studi in memoria di Michel Simonin, Vérone, le ${ }^{\text {er }}$ octobre 2010, (sous presse).

9. Sur les rapports avec M. Flaminio, cf. Gorris Camos, Sous le signe de Pallas: paroles ailées et ascension de l'esprit dans l'Olive cit., p. I 88 sq.

ı. Cf. le sonnet I 2 de Vittoria Colonna (éd. cit., p. 9I) qui développe la métaphore de l'arbre, qui «vivo ramo», «umor verde», devient «quasi secco» pour retrouver en Christ une nouvelle vie: «Padre eterno del Ciel, se, Tua mercede, / vivo ramo son io ne l'ampia e vera / Vite ch'abbraccia il mondo e Seco intera / vuol la nostra virtù solo per fede, / l'occhio divino Tuo languir mi vede / per l'ombra intorno a le mie frondi nera / s'a la soave eterna primavera / il quasi secco umor verde non riede. / Purgami sì ch'io rimanendo Teco / mi cibi ognor de la rugiada santa / e rinfreschi col pianto la radice. / Verità sei; dicesti d'esser meco; / vien dunque omai, sì ch'io frutto felice / faccia in Te degno di sì cara Pianta».

i I. Sur le thème du dessèchement qu'évoque la devise Discessu Languet Amata («L'arbre, le saule, qui sèche loin de l'eau») accompagnant l'emblème du saule 
déjà cité, voir: s. 9, 8 «Fera ses fleurs dessecher par grand'ire»; s. I 2, 7 «Qui pouvez seulz la playe dessechen»; s. 97, , «De son beau teint la frescheur dessechée». Pour l'épithète «sec», voir: s. 3 I, 8 «Et toute fleur devient seiche et fenée»; s. 32, 9 «De ton printemps les fleurettes seichées»; s. 69, I 2 «La, mes escritz fueille seiche deviennent»; s. 98, I «S’il a dict vray, seiche pour moy l'ombrage»; s. I03, I «Mais quel hiver seiche la verde souche». Voir aussi Petrarca, Rvf I66, 9-ı I: «L'oliva è secca, et è ricolta altrove / l'acqua che di Parnaso si deriva, / per cui in alcun tempo ella fioriva». Nous utilisons l'édition Francesco Petrarca, Canzoniere, éd. M. Santagata, Milan, Mondadori, 2004, pp. I4I 3-32.

I 2. Cf. la belle et touchante «Introduction» de Tina Caldarini à JоAснім Du Bellay, La Monomachie de David et de Goliath. Ensemble plusieurs autres cuvres poetiques, Genève, Droz, I98 I, pp. 7-39. Son édition de L'Olive avait été publiée à Genève chez Droz en 1974. Nos citations renvoient à cette édition, sauf indication contraire.

I 3. Sonnet I, «Scrivo sol per sfogar l’interna doglia», v. I 2, éd. Bullock, p. 3.

I 4. G. H. Tucker, "Ce tenebreux voyle" de L'Olive (I549; I550): formes et significations du recueil augmenté de I550 (par rapport au recueil de I549). Vers une lecture textuelle, métatextuelle et intertextuelle, in L'Olive de J. Du Bellay cit., p. 66.

I 5. Du Bellay, La Monomachie cit., p. 7 .

i6. Cf. Petrarca, $R v f$ 230, i 2-23: «Non laura né palma, ma tranquilla oliva / Pietà mi manda».

17. Voir la dépêche d'Alberto Sacrati au duc de Ferrare, datée de Joinville, le I 4 août I 540, in Carteggio di Vittoria Colonna, marchesa di Pescara, Ermanno Ferrero et Giuseppe Müller édd., Turin, Loescher, r 889, pp. 204-205. D. Tordi a identifié le «libro di sonetti» dans le codex Ashburnham in 33 de la Bib. Laurenziana (L dans l'éd. Bullock, éd. cit., p. 238): SONETTTI DE PIU ET DI/VERSE MATERIE DELLA/ DIVINA SIGNORA VITTORIA/COLONNA MARCHESA DI/ PESCARA CON SOMMA DILI/GENZA REVISTI ET/ CORRETTII NEL/ ANNO. M./D./XL././ Voir Il codice delle rime di Vittoria Colonna marchesa di Pescara appartenuto a Margherita d'Angoulême regina di Navarra, scoperto ed illustrato da Domenico Tordi, Pistoia, Lito-tipografia G. Flori, I900, pp. 23-35. Toujours Sacrati écrit que: «Alli passati essendomi stato indirizzato un libretto di sonetti scritti a mano della Signora Marchesa di Pescara da un gentiluomo mio compare, acciò gli avessi a da presentare alla serenissima reina di Navarra in nome suo, per haver sua Maestà fatto ricercar lui de detti sonetti par mons. De Rodes, et per esser gentilhuomo gran servitore della Marchesa». Cf. Campori, Vittoria Colonna, cit., p. 28; Tordi, Il codice cit., p. I 9; Simoncelli, Pietro Bembo cit., pp. 49-50. Pour les rapports entre Vittoria et la reine de Navarre, voir: V. L. Saulnier, Marguerite de Navarre, Vittoria Colonna et quelques autres amis italiens de I540, in Mélanges à la mémoire de Franco Simone. France et Italie dans la culture européenne, I, Moyen Âge et Renaissance, Genève, Slatkine, I980, pp. 28 I-95; B. Collett, A Long and Troubled Pilgrimage: the Correspondence of Marguerite d'Angouleme and Vittoria Colonna, I540-I545, in Studies in Reformed Theology and History, New series, VI, Prin- 
ceton (NJ), Princeton Theological Seminary, 2000 et, surtout, S. M. Pagano, C. Ranieri, Nuovi documenti su Vittoria Colonna e Reginald Pole, Città del Vaticano, Archivio Vaticano, 1989, pp. 72-74 . Cf. aussi T. R. Toscano qui propose une nouvelle hypothèse: selon lui l'intermédiaire n'est pas Gualteruzzi, mais Bembo lui-même qui avait pu obtenir les poèmes de Vittoria, toujours très réticente à les diffuser et à les publier, cf. VitToria Colonna, Sonetti. In morte di Francesco Ferrante D'Avalos Marchese di Pescara (Edizione del ms. XIII. G. 43 della Biblioteca Nazionale di Napoli), Tobia R. Toscano éd., Milan, Mondadori, I 998, p. 24 sq. Il cite l'édition critique des lettres de Bembo (Pietro Bembo, Lettere, éd. E. Travi, Bologne, IV, I 993, p. 606) où le poète écrit «Alla Regina di Francia» de lui avoir fait «trascrivere e ridurre in un picciolo volumetto, nudo d'ogni esteriore ornamento» les Rime spirituali de la Marquise de Pescara. Voir aussi une autre lettre (pp. 606-607) où on évoque l'envoi de «cento molto belli sonetti della Ill.ma Sig.ra Marchesana di Pescara, tutti religiosi e santi, dettati dal suo leggiadrissimo ingegno in così breve spazio che non si crederebbe di leggieri da chi veramente nol sapesse come sa egli». Vergerio écrit en I 540 (Lettere volgari di diversi, Venise, i 544 , f. I 26) d'avoir vu «le rime della Marchesa [...] in mano della Regina». Ce dernier ms. semble avoir disparu.

I 8. Elle offre des recueils manuscrits en don à ses amis, cf. Tordi, Il codice cit., p. I 9 et C. Vecce, Vittoria Colonna: il codice epistolare della poesia femminile, in Les femmes écrivains en Italie au Moyen Age et à la Renaissance, Actes du Colloque international de Aix-en-Provence, les I 2-I 4 novembre I992, Université de Provence, I 994, p. 2 I 4 ; elle donne, par exemple, à Michelangelo, autour de I 540 , un cahier contenant I 3 sonnets «spirituali» (Vat. Lat. I I 539 - V2), cf. Dionisotti, Appunti sul Bembo cit., p. I 34 et p. I 38 ; à Francesco della Torre un ms. (ms. II.IX.30, B.N. de Florence) contenant cent poèmes; à Marguerite de Navarre elle envoie un livre sans reliure contenant IO2 poèmes (7 I «spirituali», I9 «amorose» et I 2 «epistolari»); le ms. présentait un sonnet en français à la fin, ce qui a fait supposer que Jeanne d'Albret l'avait hérité. Il est aussi possible que le ms. ait été apporté en Italie par Marguerite qui possédait dans sa bibliothèque d'autres mss. de sa tante et marraine. Cf. Gorris Camos, La Bibliothèque de la duchesse cit. Pour le don à Marguerite, cf. A. Brundin, Vittoria Colonna and the Spirituals Poetics of the Italian Reformation, Burlington, Ashgate, 2008 et surtout le chap. IV, «The Gift Manuscript for Marguerite de Navarre», pp. IоI-I 3, mais l'auteur ne connaît pas la mise à point de Toscano.

I 9. Pour une description de ces éditions, cf. éd. Bullock cit., p. 258 sq.

20. Un exemplaire de l'édition de I 540 est conservé à la Biblioteca de la Fondation Galletti de Domodossola : RIME DE LA DIVA/VETTORIA COLONNA DE/pescara inclita Marchesana/NOVAMENTE AGGIUNTOVI/XXIIII. Sonetti Spirituali, \& le sue stanze,/ \& uno triompho de la croce di Chri/sto non piu stampato con/ la sua tauola. [portrait de Vottoria] /IN VENETIA MDXXXX (In Venetia: per Comin de Trino: ad instantia de Nicolo d'Aristotile, detto Zoppino, I 540]. Nous remercions Angela Casagrande de la Bibliothèque Contini qui nous a fait parvenir un PDF de la rare édition qui contient un sonnet important pour l'intertexte de l'Olive (voir infra). Cf. la page de titre ci-dessus (fig. I) où l'on voit une femme en habit religieux qui regarde le Christ en croix; ce choix iconographique voulait mettre en relief «la giunta spirituale». Cette édition 
s'ouvrait sur les «rime spirituali», le Trionfo di Croce et 3 I sonnets religieux. Cf. Dionisotti, Appunti sul Bembo cit., p. 282.

21. Les exemplaires conservés à Turin sont les suivants: Le rime spirituali della illustrissima signora Vittoria Colonna marchesana di Pescara. Non piu stampate da pochissime infuori, le quali altroue corrotte, \& qui corrette si leggono, In Vinegia al segno di San Giorgio, I 548 (In Vinegia: per Comin da Trino di Monferrato, I 548 ) (B.N. de Turin, MSC.262/4 et F.XI.I93. Dans le paratexte de l'édition de I 548 la poésie est considérée comme «un dono di Dio conceduto a mortali, acciocché, come affermano ancora gli scrittori gentili, potessero lodare esso Dio, e gli huomini divini con uno stile più magnifico, e più sublime che non è quello delle prose». La poésie des «cose celesti» de Vittoria «risplende, che sì faccia la luna fra le minor stelle» et permet de «conseguire la vera immortalità» (f. A ij). Le rime spirituali della illustrissima signora Vittoria Colonna marchesana di Pescara. Non piu stampate da pochissime infuori, le quali altroue corrotte, et qui corrette si leggono, In Vinegia, appresso Vincenzo Valgrisi, I 546 (BN de Turin, Rés. 26.7). Cf. sur l'importance de l'édition de I 548: Rime sacre dal Petrarca al Tasso, M. L. Doglio et Carlo Delcorno édd., Bologne, Il Mulino, 2005 , p. I I qui affirme que «l'edizione delle Rime spirituali di Vittoria Colonna (I 548), è decisiva per l'affermarsi di una specifica sezione "religiosa" della poesia italiana».

22. Par ex. la B. N. de Turin conservait le Ms. de dédicace des Rime de Bandello (Alcuni fragmenti de le rime di Bandello, B.N., Codex CXXXVI.k.I.33) que Marguerite avait apporté dans ses coffres; le ms. a brûlé en I904, lors de l'incendie de la Bibliohèque Nationale; les fragments qui restent sont conservés sous la cote: N.VII.7I, Voir Gorris Camos, "Questi bei fior e pallide viole» cit.; un manuscrit de la traduction de Du Bellay du De initiatione sermo de L'Hospital (CLIII.k.I.7 I: cote: L.V.40) qui a aussi disparu dans le feu; le Ms. du livre III (Codex LXIX k.I.I 37 , cote: L.V.28) et IV (Codex CXVIII.1.V.25, cote: L.III.I9) de la Franciade ont aussi été gravement endommagés par le feu; seul le livre IV est rescapé et il a été identifié par le regretté professeur Vitale Brovarone de l'Universitè de Turin; en I 983 , il a fait l'objet d'une restauration par le laboratoire Pietro Gozzi de Modène (cf. la documentation contenue dans la boîte qui conserve le Ms. L.III.r 9). Sur ces Mss. voir le catalogue de B. Peyron, Codices Italici manu exarati qui in Bibliotheca Taurinensis Athenaei ante diem 26 ianuarii M.CM.IV asservabantur / recensuit, illustravit Bernardinus Peyron; praemittuntur C. Frati Italica praefatio et elenchus operum B. Peyroni typis impressorum, Taurini, apud C. Clausen, 1904 (Ex Off. Typ. Regia J. B. Paravia et Soc.), pp. 273-74 pour Bandello et celui de G. Pasini, Codices manuscripti Bibliothecae Taurinensis Athenei, Pars Altera, Taurini, ex Typographia Regia, MDCCXLIX où ils sont décrits (p. 480 et p. 489 pour Ronsard; p. 497 pour Du Bellay). Avec les Rime de Bandello, la traduction de L'Hospital de du Bellay et le livre III de Franciade de Ronsard ont brûlé d'autres manuscrits qui faisaient partie de la riche bibliohèque de Marguerite, par exemple le Ms. de la Città del vero de Baccio del Bene (CCLXXXII, N.VI.7, cf. Peyron cit., p. I 89), dont nous avons retrouvé en Allemagne une autre copie; un ms de La Sphinge de Valerio Saluzzo della Manta, magnifique don de l'auteur à Marguerite pour son mariage (un autre ex. est conservé à la Bib. Royale de Turin); le manuscrit des poèmes de Pierre Demay écrits pour le baptême de Charles-Emmanuel, LXX.k.I.I 39, cote: L.V.2 I); le ms. original de l'Ode à Madame Marguerite de France duchesse de Savoie (CLVII.k.I.9o, 
cote: L.V.66 de rebuttet). En I 574, a paru à Turin, chez Giovan Francesco Pico, une édition de Les Quatre premiers livres de la Franciade, Turin, Jan François Pico, I 574, in- $16^{\circ}$ (cf. Bersano-Begey, I, 337, nn. 460-46I).

23. Colonna, Rime, éd. Bullock, p. i 58.

24. Colonna, Rime, éd. Bullock, p. 74.

25. Colonna, Rime, éd. Bullock, p. 60.

26. Colonna, Rime, éd. Bullock, p. 32.

27. Colonna, Rime, éd. Bullock, p. 25. L'adjectif «amen» revient 6 fois dans l'Olive, voir: s. 45 , I 2 «Et de son fruict amer me repaissant»; s. 52, 5 «Toy, qui le doulx mesles avec l'amer»; s. 55, 6 «O doulx sçavoir, trop amer à comprendre»; s. 77, 2 «De mon amer la tant douce racine» (écho à Pétrarque, $R v f$ 229, I 4 «Si dolce è del mio amaro la radice»); s. 93, I 4 «Tant mon amer a la racine doulce»; s. I07, I 3 «S'il a goûté l'amer de mes douleurs». Voir aussi H. Tucker, Formes et significations de l'olivier-oleaster: une esthétique du doux-amer et du clair-obscur, in "Ce tenebreux voyle" de L'Olive cit., p. 63 sq. Cf. le Relevé complet après lemmatisation dans le CD réalisé par Éric Lysøe, à l'occasion du Colloque de Lucelle.

28. Cf. par exemple le magnifique s. i 5 , éd. Bullock, p. 63, qui concentre la quintessence du lexique de l'Olive : du verbe «adoren» au lexique de l'envol («m'involo», «l'ali non spiega», «volo»), la dialectique entre amour profane et amour sacré («qui» / «là»), la terre («mondan diletto») et le ciel («ben perfetto»): «Vivo su questo scoglio orrido e solo / quasi dolente augel che 'l verde ramo / e l'acqua pura aborre, e a quelli ch'amo / nel mondo ed a me stessa ancor m'involo / perché expedito al Sol ch'adoro e colo / vada il pensiero, e se ben quanto bramo / l'ali non spiega, pur, quand'io il richiamo, / volge da l'altre strade a questa il volo, / e 'n quel punto che giunge lieto e ardente / là 've l'invio, sì breve gioia avanza / qui di gran lunga ogni mondan diletto. / Ma se potesse l'alta sua sembianza / formar quant'ella vuol l'accesa mente / parte avrei forse qui del ben perfetto».

29. Voir R. Fedi, Michelangelo, e la "forma canzoniere", in Incontri con Vittoria Colonna, Actes des Journées d'Études, les 26 janvier-2 mars 2006, Franco Cristelli éd., Colle di Val d'Elsa, Protagon, 2007, pp. 17-38 et Id., "L'imagine vera»: Vittoria Colonna, Michelangelo, e un'idea di canzoniere, «Modern Language Notes», vol. I07, n. I, Italian Issue (janvier I 992), pp. 46-79 où il parle de «divaricazione che, da una parte ammetteva la disponibilità dei rimatori alluvionali ma dispersi nelle antologie di metà secolo, e dall'altra avrebbe condotto di lì a qualche anno alla sacralità tassiana, drammaticamente oppositiva. La Colonna era, di questa crisi, lo specchio evidente, divisa anch'essa da un certo momento in poi tra sacro e profano: e si può affermare che Michelangelo cogliesse, nelle figure bifronti delle sue donne poetiche, il senso di quel dibattito e di quella lacerazione, lui poco interessato alla definizione grammaticale e imitativa e molto, invece, ad una rilettura approfondita e ideologica di quell'esperienza» (p. 78) ou encore de «incrocio fra opzione formale e necessità spirituale» (p. 78), mais aussi de «irriducibile frattura» (p. 79). Voir aussi Fedi, La memoria della poesia. Canzonieri, lirici e libri di rime nel Rinascimento cit. 
30. Fedi, «L'immagine vera» cit., p. 78.

31. Cf. les Actes du Colloque European Petrarchism. Reading and Writing Petrarch in the Renaissance cit. Voir aussi la Petrarkismus-Bibliographie 1972-2000, herausgegeben von Klaus W. Hempfer, Gerhard Regn, Sunita Scheffel, Stuttgart, Franz Steiner Verlag, 2005.

32. Cf. A. Quondam, Riscrittura-Citazione-Parodia del codice. Il «Petrarca spirituale» di Girolamo Malipiero, «Studi e Problemi di Critica Testuale», I7 (1978), pp. 77-I 25 ; Id., Note sulla tradizione della poesia spirituale e religiosa, in Pietosi affetti. Il madrigale spirituale nell'Italia del Cinque-Seicento, Venise, Fondazione Giorgio Cini, octobre 2000 (étude en ligne). Voir aussi S. Carrai, La lirica spirituale del Cinquecento, in L'usignolo del Bembo. Un'idea della lirica italiana nel Rinascimento, Rome, Carocci, 2006, pp. I 23-35.

33. I. Pantani (dir.), Libri di poesia, Milan, Editrice Bibliografica, I996; Id., La fonte d'ogni eloquenza. Il canzoniere petrarchesco nella cultura poetica del Quattrocento ferrarese, Rome, Bulzoni, 2002.

34. Juan de Valdes, Lo evangelio di San Matteo, éd. C. Ossola, Florence, Sansoni, I 974 .

35. Sur Michelangelo, voir les récents travaux d'Antonio Corsaro de l'Université de Urbino qui dirige un PRIN sur La parola, il testo, l'immagine nell'età della Riforma (I530-1600): A. Corsaro, Michelangelo e la lirica spirituale del Cinquecento, in Ludovico Castelvetro. Letterati e grammatici nella crisi religiosa del Cinquecento, Actes de la XIII ${ }^{\mathrm{e}}$ journée en l'honneur de Luigi Firpo, Turin, les 21-22 septembre 2006, M. Firpo et G. Mongini édd., Florence, Olschki, 2008, pp. 26r-84; Id., Michelangelo e i letterati, in Officine del nuovo. Sodalizi fra letterari, artisti ed editori nella cultura italiana fra Riforma e Controriforma, H. Hendrix et P. Proccaccioli édd., Manziana, Vecchiarelli, 2008, pp. 383-425; Id., Intorno alle Rime di Michelangelo Buonarroti. La silloge del 1546, "Giornale Storico della Letteratura Italiana», CLXXXXV, fasc. 6 2 (2008), pp. 536-69. Voir aussi sur ses positions religieuses et ses rapports avec Vittoria: E. Campi, Michelangelo e Vittoria Colonna: un dialogo artistico-teologico ispirato da Bernardino Ochino e altri saggi di storia della Riforma, Turin, Claudiana, I994; Vittoria Colonna e Michelangelo, P. Ragionieri éd., Florence, Mandragola, 2005, pp. 97-105; M. Forcellino, Michelangelo, Vittoria Colonna e gli "spirituali": religiosità e vita artistica a Roma negli anni Quaranta, Roma, Viella, 2009 (CR en UM 36 par Maria Grazia Dalai). Pour une bibliographie en ligne des ouvrages sur Michelangelo, voir Michelangelo Buonarroti. Selezione bibliografica I97I-20I0, réalisée par A. Corsaro et S. Dubovic et publiée sur le site de Cinquecento plurale à l'adresse: bttp://www.nuovorinascimento.org/cinquecento/mich-biblio.pdf.

36. On relève 26 récurrences du mot «nuit» et 9 du mot «voyle» dans l'Olive, cf. le Relevé complet après lemmatisation dans le CD réalisé par Éric Lysøe, à l'occasion du Colloque de Lucelle. Le thème de la nuit est obsédant dans les Rime de Colonna, cf. par exemple le sonnet 68, v. 2, éd. Bullock, p. 37: «che 'l nero manto de la notte sgombra» et le magnifique sonnet 76 Se per serbar la notte il vivo ardore, éd. Bullock, p. I 23 et cf. surtout les vv. 9-10: «se s'apre in questa fredda notte oscura / per noi la porta a l'inimico vento». 
37. Cf. Colonna, Rime, éd. Bullock.

38. Cf. Colonna, Rime, éd. Bullock, p. 38.

39. O. Millet, Présence de Virgile dans l'Olive de Du Bellay, in Les Fruits de la saison. Mélanges de littérature des XVI et XVII siècles, offerts au professeur André Gendre, Genève, Droz, 2000, pp. I05-I 8 et Id., Du Bellay et Pétrarque, autour de l'Olive, in Les poètes français de la Renaissance et Pétrarque cit., p. 258 sq. Voir aussi la belle édition de O. Millet in Joachim Du Bellay, L'Olive in Euvres complètes, Paris, Champion, 2003.

40. Cf. Imitation de l'Ode precedente de I.D.B.A.: «Comme en un char, qui brusloit / Ravy parmy l'air liquide, / Le grand Prophete voloit, / Et commandant à la bride / Des chevaux audacieux, / D'une main étincelante / Guidoit leur trace brulante / Par la carriere des cieux» (f. $\mathrm{H} 5 \mathrm{v}^{\circ}$ ), in LE/TOMBEAU/DE MARGUERITE DE VA-/LOIS ROYNE DE NAVARRE./Faict premierement en Disticques latins par les trois Sœurs/Princesses en Angleterre. Depuis traduictz en Grec, Italien/ et François par plusieurs des excellentz Pœtes de la France./Avecques plusieurs Odes, Hymnes, Cantiques, Epi-/taphes, sur le mesme subject /A PARIS,/ [marque] /De l'imprimerie de Michel Fezandat, et Robert Granlon/au mont S. Hilaire à l'enseigne des Gran lons, et au Palais/en la boutique de Vincent Sertenas./I 55 I/AVEC PRIVILEGE DU ROY // (Ars., $8^{\circ}$ BL 11833 Rés. et BnF, Rés. Ye I633). Voir aussi la version italienne de Jean-Pierre de Mesmes (f. H iij): «sì come il Propheta rapito Elia».

41. Tutte le rime della illustrissima et eccellentissima signora Vittoria Colonna, Marchesana di Pescara con l'espositione del signor Rinaldo Corso, Venezia, Giovambattista et Melchior Sessa, I 558. Corso avait déjà publié une première version de son commentaire dans sa Dichiaratione fatta sopra la seconda Parte delle Rime della Divina Vittoria Collonna Marchesana di Pescara da Rinaldo Corso, Bologne, Faelli, i 543 (deux exemplaires à la B.N. de Florence, un ex. à la Marciana et un ex. à la British Library de Londres). Sur ce commentaire voir C. Cinquini, Rinaldo Corso editore e commentatore delle Rime di Vittoria Colonna, in «Aevum», LXXIII, 3 (septembre-décembre I 999), pp. 66996; M. Bianco, Rinaldo Corso e il Canzoniere di Vittoria Colonna, in "Italique», I ( 1998$)$, pp. $35-45$ et Ead., Le due redazioni del commento di Rinaldo Corso alle Rime di Vittoria Colonna, in «Studi di filologia italiana», 56 (1998), pp. 27 I-95 et C. Ranieri, V. Colonna dediche, libri e manoscritti, in «Critica letteraria», XIII (I985), p. 249. Sur la vie du véronais R. Corso, secrétaire et lecteur de Veronica Gambara, cf. DBI, tome 29, I993, ad vocem et R. Finzi, Un correggese del Rinascimento: Rinaldo Corso (I525-I582), Modène, Aedes Muvitoriana, I959. En I 545, il adresse à Barbara da Correggio la préface de la traduction de la Vorrede de Luther: Prefatione del Reverendiss. Cardinal Federico Fregoso nella Pistola di san Paolo a' Romani, Venise, Comin da Trino, I 545. Cf. S. Seidel Menchi, Le traduzioni italiane di Lutero, in «Rinascimento», i 7 (I 977), pp. 8I-Io6.

42. Cf. Gorris Camos, Sul II2 dell'Olive cit. et Ead., Sous le signe de Pallas cit., pp. I67-232. Voir sur la Cour de Correggio, centre très actif d'études de la poésie de Vittoria: G. Fragnito, Girolamo da Correggio, DBI, tome 29, I993, et Veronica Gambara e la poesia del suo tempo nell'Italia settentrionale, Actes du Colloque de Brescia-Correggio, I7-19 octobre 1985, C. Bozzetti, P. Gibellini, E. Sandal 
édd., Florence, Olschki, 1989 et notamment A. Ghidini, La contea di Correggio ai tempi di Veronica Gambara, pp. 79-98. Voir aussi Veronica Gambara, Le Rime, A. Bullock éd., Florence- Perth, Olschki, r995.

43. Tutte le rime della illustrissima et eccellentissima signora Vittoria Colonna marchesana di Pescara con l'espositione del signor Rinaldo Corso cit., f. Io sq.

44. Colonna, Rime, éd. Bullock, p. 23.

45. Colonna, Rime, éd. Bullock, p. I94.

46. Voir M. Bianco, Rinaldo Corso cit.

47. Cf. Gambara, Le Rime, A. Bullock éd. cit., p. 44. Sur ces échanges de vers, cf. par ex. Tutte le rime della illustrissima et eccellentissima signora Vittoria Colonna marchesana di Pescara con l'espositione del signor Rinaldo Corso cit., où l'on trouve deux sonnets de Veronica: f. 389, «Mad. V. Gambara di Coreggio alla Signora Marchesa» et f. 399, «Della medesima». Cf. éd. Bullock, n. 4I et n. 42. Giraldi Cinthio les associe dans un même éloge: «fuere pene non viris inferiores», «quorum utriusque pro sexus qualitate divina leguntur poemata», cf. Due dialoghi sui poeti dei nostri tempi, éd. C. Pandolfi, Ferrare, Corbo, 1999, pp. 220-2 I. Sur leurs rapports et sur la «consacrazione di uno specifico femminile» opérée par Bembo qui inclut deux leurs sonnets dans ses Rime, cf. Vecce, Vittoria Colonna cit., p. 2 I 3 sq.

48. Il témoigne sans doute de l'importance des Rime de Vittoria pour ses contemporains, de son rôle de premier plan dans la poésie contemporaine et de la dimension lyrique et esthétique «haute» de ses poèmes, issus de son expérience religieuse et spirituelle.

49. Tutte le rime della illustrissima et eccellentissima signora Vittoria Colonna marchesana di Pescara con l'espositione del signor Rinaldo Corso, f. 240 sq.

50. Le Phénix est évoqué par Du Bellay in: s. 36, i 2 «Puis qu'ay pour toy du Phenix le semblant»; s. 79, 4 «Comme un Phenix faict ses aesles mouvoin»; s. I I7, I66 «Manier sous un Phenix». Cf. sur cette image du Phénix, Tucker, "Ce tenebreux voyle" cit., p. 89 sq., qui associe au Phénix un autre mythe du feu, «fondamental dans la poétique bellaïenne», le mythe de Sémélé, «emblème d'une initiation artistique intellectuelle et spirituelle» (p. 90). Voir aussi Petrarca, Rvf I 35 Qual più diversa e nova, vv. 5-8.

5 I. Cf. éd. Caldarini, pp. 9I-92.

52. Le Ms. de la BRT, Var. 65 est sans doute le ms. de don que Guy de la Garde avait offert à la princesse avant la publication chez Chaudière. Le texte, qui commence par l'épître dédicatoire (les deux premiers ff. de l'édition manquent), contient le poème, mais la deuxième partie de l'ouvrage qui en explique le sens allégorique, «le sens soubs luy compris» (Du Phoenix. L'explication du Phoenix, f. D iij), manque. Dans le recueil, relié aux armes des deux mariés, le lys et la croix (BRT, Varia I03), on trouve le Destin du tres-heureux et passificque mariage, dédié aux ducs de Savoie par l'auteur, «gentilhomme du pais de Languedoc, [...] treshumble 
tresobeissant et affectionné serviteur» (f. 2), et une traduction de l'auteur: I. LE/DESTIN DU TRES-/heureux et passificque mariage/ de treshaut, trespuissant, et/tresillustre Philibert Ema-/nuel Duc de Savoye et /Prince de Piemont/par l'aucteur de/l'histoire du/phoenix./PLUS LADICTE HISTOIRE DU/ phoenix à l'honneur et louange de /Madame./L'ORAISON FUNEBRE SUR LES LOUAN-/ges des heroiques vertus de Evagore/Roy de Chipre.//.2. L'HISTOIRE/ ET DESCRIPTION DU/PHOENIX/COMPOSE/A L'HONNEUR ET LOUAN-/ge de treshaute et tresillustre princesse, Madame/Marguerite de France, sœur unique du /Roy. Par Maistre Guy de la Gard-/de, escuier de Chambonas, Lieu-/tenant du Seneschal de /Provence, au siege/D'Arles.// marque/ A PARIS/De l'imprimerie de Regnaud Chauldiere/ et Claude son fils/I 550//[44] c.: ill.; $8^{\circ}$. (Segn. A8-E8 F4). Et une traduction d'Hisocrate: 3. ORAISON/FUNEBRE SUR/LES LOUANGES DES/heroiques vertus de/Evagore Roy de Cypre,/ Traduite par G. de la Garde con-/seiller, et lieutenant particu-/lier de seneschal de Pro-/vence au siege/d'Arles/Desdiée à treshaut, et excellent Prince(Emmanuel Philbert duc de Savoie,/A Lyon/par Benoist Rigaud, I 562.// 38, [2] c.; $8^{\circ}$ - cahiers: A-E8 Voir sur cet ouvrage cf. Gorris Camos, La Bibliothèque de la duchesse cit.

53. Un exemplaire est conservé à la BnF, Rés. Ye I648. G. H. Tucker nous a signalé un exemplaire de luxe de cet ouvrage, imprimé sur vélin, conservé à la British Library de Londres (cote: G. 10992) qui pourrait être un exemplaire de don, offert à la princesse par l'auteur. Sur le thème du Phénix, voir R. Cooper, The Philosophical Phoenix, in Philosophical Fictions and the French Renaissance, ed. Neil Kenny, London, The Warburg Institute-University of London I991, pp. 71-87 et B. Basile, La fenice da Claudiano a Tasso, Rome, Carocci, 2004.

54. La dévotion de Guy de La Garde à la princesse va augmenter au fil des années pour trouver son sommet dans le manuscrit offert aux ducs de Savoie à l'occasion de leur mariage.

55. Sur les rapports entre Marguerite et Guy de la Garde, voir Gorris Camos, Sous le signe de Pallas cit., pp. 167-232. Sur d'autres mss. offerts comme dons de mariage, cf. Gorris Camos, La Bibliothèque de la duchesse cit., passim.

56. Cf. Nuovi documenti su Vittoria Colonna e Reginald Pole, Città del Vaticano, Archivio Vaticano, 1989, pp. 72-74.

57. Cf. E. Belligni, Evangelismo, Riforma ginevrina e nicodemismo. L'esperienza religiosa di Renata di Francia, Cosenza, Brenner, 2008.

58. Juan de Valdes, Lo evangelio di San Matteo cit.

59. Forcellino, Michelangelo, Vittoria Colonna e gli "spirituali” cit.

6o. M. Forcellino, I disegni e dipinti di Crocefissione e Pietà per Vittoria Colonna e i suoi amici, in Michelangelo, Vittoria Colonna e gli "spirituali" cit., p. 65-66. Sur la croix un vers de Dante: «Non vi si pensa quanto sangue costa» (Paradiso 29, 91).

61. Forcellino, I disegni e dipinti cit., p. 68, n. 28. Voir le magnifique Pianto della Marchesa di Pescara sopra la Passione di Christo, con una Oratione della medesima, sopra 
l'Ave Maria. [Aggiuntavi una] Oratione fatta il venerdi santo, sopra la passione di Christo, In Vinegia appresso Gabriel Giolito de' Ferrari, MDLXII [première édition: Venise, Alde, I 5 6]. Voir sur cet ouvrage et sa fortune, P. Simoncelli, Evangelismo italiano del Cinquecento: questione religiosa e nicodemismo politico, Istituto storico italiano per l'età moderna e contemporanea, I979, pp. 209-25 et pp. 423-44 où il en publie le texte.

62. Forcellino, I disegni e dipinti cit., p. 78, n. 65 .

63. Cf. Corsaro, Projet PRIN, en ligne.

64. M. Firpo, Vittoria Colonna, Giovanni Morone e gli spirituali, in «Rivista di storia e letteratura religiosa», XXIV (I988), pp. 2 гі-6г. Voir aussi du même auteur: Il Beneficio di Christo e il Concilio di Trento (I542-I546), in "Rivista di storia e letteratura religiosa», XXXI (1995), I, pp. 45-72; Id., Pietro Carnesecchi, Caterina de' Medici e Juan Valdès. Di una sconosciuta traduzione francese dell'Alphabeto Christiano, in Dissenz und Toleranz im Wandel der Geschichte, Festschrift zum 65. Geburstag von H. R. Guggisberg, Mannheim, Palatium Verlag, 1996, pp. 75-88. G. Fragnito, Vittoria Colonna e l'Inquisizione, in «Benedictina», 37(1990), pp. I 57-72.

65. Cf. R. Gorris Camos, «Sotto un manto di gigli di Francia»: poésie, allégorie et emblèmes de la dissidence entre Ferrare et Turin, in Allégorie, symbole et dissidence (Antiquité, MoyenAge, Renaissance), Acte du Colloque international de Nantes, ${ }^{\text {er }}{ }_{-3}$ décembre 2009, Anne Rolet éd., Rennes, Presses Universitaires de Rennes 201 2, pp. 439-496.

66. Cf. les études récentes de Corsaro et son récent Michelangelo Buonarroti, in Autografi dei letterati italiani, Il Cinqucento, I, M. Motolese, E. Russo, P. Procaccioli édd., Rome, Salerno, 2009, pp. 73-93.

67. Cf. Corsaro, Projet PRIN, en ligne.

68. O. Moroni, Carlo Gualteruzzi (I500-I577) e i corrispondenti, Città del Vaticano, Biblioteca Apostolica Vaticana, I984.

69. Gorni, I tempi dell'Olive cit., p. 8I.

70. Libro primo delle rime spirituali, Venezia, al segno della Speranza, i 550. Cf. Corsaro, Michelangelo e la lirica spirituale del Cinquecento cit., p. 274 et G. Auzzas, Notizie su una miscellanea veneta di rime spirituali, in Rime sacre dal Petrarca al Tasso cit., pp. $205-20$.

7I. Cf. E. Barbieri, Fra tradirione e cambiamento: note sul libro spirituale del XVI secolo in Libri, biblioteche e cultura nell'Italia del Cinque e Seicento, Milan, Vita e Pensiero, 2002, p. 22.

72. Cf. Dionisotti, Appunti sul Bembo cit., n. 73.

73. Voir l'article de Giovanni Bardazzi, Le rime spirituali di Vittoria Colonna e Bernardino Ochino, in «Italique», IV (200I), pp. 62-ı I qui écrit: «L'immagine della devota assorta in preghiera poteva essere facilmente accostata, nel frontespizio delle Prediche e, già prima, dei Dialogi, all'immagine di un frate barbuto dall'ampio 
saio e dal largo cappuccio, la tonsura scoperta, le mani giunte, gli occhi rivolti a un crocifisso raggiante, del quale l'incisore ha saputo rendere con linee fitte il sovrabbondare di luce.»

74. Campi, Michelangelo e Vittoria Colonna cit., p. 39 sq. qui parle de «mediazione ochiniana» et Firpo, Vittoria Colonna, Giovanni Morone e gli "spirituali" cit., p. 2 I I sq.

75. Christ est «il vero amante» (s. I 2, éd. Bullock, p. I 83) qui a tout donné en échange de nos erreurs: «a noi diede il Suo amore / divino, e per Sé prese il nostro errrore/umano» (s. I 2, vv. 6-8). Voir Campi, Michelangelo e Vittoria Colonna cit., p. 40 sq. qui parle de «una fede orientata e fondata su Cristo» p. 44, et Bardazzi, Le rime spirituali cit. Campi ajoute que «l'idea che l'uomo non è accolto da Dio per una sua intrinseca giustizia, ma per la giustizia che viene dalle piaghe del Crocifisso, scorre come un filo d'oro attraverso tutte le Rime», p. 48.

76. Voir aussi le s. 54, v. 5, Colonna, Rime, éd. Bullock, p. i i 2: «erge tant’alto il mio basso desio».

77. Voir sur le topos évangélique de la tempête, D. Crouzet, Une tempête évangélique, in La sagesse et le malheur. Michel de l'Hospital Chancelier de France, Seyssel, Champ Vallon, I998, pp. 27-100. Voir aussi P. Galland, L'opportune tempête, in Le "Génie" latin de Joachim du Bellay, La Rochelle, Rumeur des Ages, i995, p. I4. Sur l'Iter Nicoeum, voir R. Gorris Camos, «Tempestes», in «Sotto un manto di gigli di Francia» cit., p. I 8 sq.

78. Colonna, Rime, éd. Bullock, p. 96.

79. Grévin a traduit les Sermons de B. Occhin en françois. Nouvellement mis en lumiere à l'honneur de Dieu, profit et utilité de tous fideles Chrestiens desirans vivre selon la Loy du Seigneur et des saincts commandemens, I 561, I80 - 3 ff. (BnF, D2 974 et B.N. de Florence, Fonds Guicciardini, 2-6-28). Cf. Bernardino Ochino, I Dialogi sette e altri scritti del tempo della fuga, éd. U. Rozzo, Turin, Claudiana, 1985 ; Id., Seven Sermons preached in Patria by Bernardino Ochino 1487-I464, éd. Ph. Mc Nair, Cambridge, Anastasia Press, 1999. Voir sur la traduction M. Oliva, Jacques Grévin traducteur d’Ochin, Thèse dirigée par E. Balmas, Université de Vérone, a.a. 1972-73.

8o. Colonna, Rime, éd. Bullock, p. 96, vv. 6-8.

81. Colonna, Rime, éd. Bullock, p. 96.

82. L'ENCYCLIE//DES SECRETS DE//L'ETERNITÉ.// A TRESHAULT ET TRES-//Illustre Prince Monseigneur le Duc//d'Allençon frere du Roy treschrestien// CHARLES neufiéme.//PAR GUY LE FEVRE DE//LA BODERIE// [marque typographique Compas d'or],// EN ANVERS,//De l'Imprimerie de Christofle Plantin,//Imprimeur du Roy catholique.//AVEC PRIVILEGE.// (B.N., Rés. Ye I052, ex. numérisé sur Gallica), f. ıо9.

83. E. Buron, Du sonnet CXIV à la dédicace, in E. Buron, N. Cernogora, Du Bellay, La Deffence et illustration de la langue françoyse, L'Olive, Neuilly, Atlande, 2007, p. 217 sq. 
84. Cf. sur ce Trionfo de l'éternité, M. C. Bertolani, Per un'indagine del lessico teologico del «Triumphus eternitatis», in Rime sacre dal Petrarca al Tasso cit., p. I7 sq.

8 5. L'image du linceul du Christ, la Vera Icona, dont l'apparition, comme dans les xoana archaïques, était attribuée à un effet prodigieux, sans intervention de la main humaine. Une image achiropoï̀te, «non bumana manu factum, sed de caelo lapsamı. Depuis lors, le portrait achiropoï̀te, la Véronique, est l'image centrale de toute l'utopie de l'image en Occident. Il y a deux versions de cette image prodigieuse: l'une est proprement chrétienne et sur son origine abondent les écrits anciens. Parmi ceux-ci, le plus connu relate que, sur le chemin du Calvaire, Jésus a séché sa sueur avec un tissu que sainte Véronique lui a tendu, et il y a laissé imprimés les traits de son visage.

86. Bertolani, Per un'indagine del lessico teologico del «Triumphus eternitatis» cit., p. I7.

87. Cf. R. Gorris Camos, I volti della duchessa: icone e rappresentazioni del potere alla Corte di Margherita di Francia, duchessa di Savoia, Il concetto del potere nel Rinascimento, Actes du Colloque de Vérone, les i6-i 8 mars 2009, Daniela Carpi éd., Vérone, Ombre Corte, 201 I, pp. 45-86.

88. Colonna, Rime, éd. Bullock, p. 5.

89. Cf. Fedi, "L'immagine vera» cit, pp. 46-73 et Campi, Michelangelo e Vittoria Colonna cit., p. 45 qui cite le sonnet 4I, éd. Bullock, p. Ios qui parut pour la première fois dans l'éd. Valgrisi de I546 et qui est à mettre en rapport avec le Christ de Michelangelo.

90. Cf. les sonnets 78-79 de l'éd. R. Conso, Tutte le rime della illustrissima et eccellentissima signora Vittoria Colonna cit.

91. Fedi, Michelangelo, e la "forma canzoniere" cit., p. 3 I.

92. Fedi, Michelangelo, e la "forma canzoniere" cit.

93. Sur Ischia, voir S. Therault, Un cénacle bumaniste de la Renaissance autour de Vittoria Colonna, châtelaine d'Ischia, Florence-Paris, Sansoni-Didier, I 968.

94. Colonna, Rime, éd. Bullock, p. 33, s. 6i, v. io.

95. Colonna, Rime, éd. Bullock.

96. J. Vignes, Introduction à Du Bellay, La Deffence et l'Olive. Lectures croisées, in «Cahiers textuels», n. 3I (2008), p. Iо.

97. Gorni, I tempi dell'Olive cit., p. 88. Pour Gorni, qui parle de «laicizzazione», il s'agit toutefois d'une poétique "pur sempre amorosa, ma non aliena da un'ispirazione metatestuale di vanto letterario» et il s'agirait de «profezia di una poesia a venire quella delle Amours ronsardiane».

98. I. Garnier-Mathez, L'épithète de la connivence. Écriture concertée chez les Évangéliques français (I523-I534), Genève, Droz, 2005, passim et J. Rieu, L'esthétique de Du Bellay, 
Paris, SEDES, I 995. Sur les Du Bellay, voir maintenant les importants travaux de Loris Petris qui a publié, en collaboration avec R. Scheurer, la Correspondance de Jean Du Bellay. Le tome IV vient de paraître: Correspondance du Cardinal Jean du Bellay, publiée pour la Société de l'Histoire de France par R. Scheurer, L. Petris et D. Amherdt, avec la collaboration de N. Guillod, tome IV, I $547-$ I 548 , Paris, Société de l'Histoire de France, 20I I, 444 pp. (la publication est complétée en ligne par une banque de données répertoriant l'ensemble de la correspondance jusqu'au dernier tome, cfr. www.unine.ch/jeandubellay)

99. LE/TOMBEAU/DE MARGUERITE DE VA-/LOIS ROYNE DE NAVARRE. cit., cf. n. 40 supra.

Io०. Cf. la dédicace, datée du 25 mars I 55 I, «A TRESILLUSTRE PRINCESSE Madame MARGUERITE, Sœur unique du Roy, Duchesse de Berry/ NICOLAS DENISOT CONTE D’ALSINOIS», ff. aiij $\mathrm{r}^{\circ}$ - f. a iiij $\mathrm{v}^{\circ}$.

ıо . Cf. par ex. le distique 3: «I.D.B.A. / La grand Royne est morte au corps, / Non en l'esprit, qui n'est ores / Gisant au nombre des mortz, / Mais vif comme il fut encores» (f. B ij và).

I02. Les épîtres dédiées à Marguerite sont nombreuses. Cf. pour une liste détaillée notre «Sotto un manto di gigli di Francia» cit.

I03. Cf. l'Epître que Michel écrit, après la Saint-Barthélemy, à la demande de Marguerite via Del Bene; dans cette épître, à cause de ses cheveux blancs, il se compare à Laërte, Epître IX, A Marguerite, duchesse de Savoie, Qui lui avait demandé quelques vers après la Saint-Barthélemy, pp. 363-69/ I 585:363-70.

I04. Sur cette amitié que «Mort n'y mord», cf. R. Gorris Camos, Va lettre, va ... droict à Clément: Lyon Jamet, sieur de Chambrun, du Poitou à la ville des Este, un itinéraire religieux et existentiel, in Les Grands Jours de Rabelais en Poitou. États des lieux (1483-I564) Rabelais et Bouchet, Actes du Colloque de Poitiers réunis par Marie-Luce Demonet, Genève, Droz, "Études Rabelaisiennes", XLIII, 2006, pp. I45-I72. Sur ces «affinités électives» et ces doubles littéraires, voir L'auteur à la Renaissance, L'altro che è in noi, Rosanna Gorris \& Alexandre Vanautgaerden édd., Turnhout, Brepols, 2009.

ıо5. Ad Margaretam Valesiam, Regiam Virginem, Francisci Regis filiam. De sacris Carminibus M. A. Flaminii, pp. 74-75/ i 5 85: 96-98: «Lis donc le poète de Venouse, sans le préférer toutefois aux précieux livres de Cicéron que tu as actuellement entre les mains; ceux-ci enseignent les devoirs de la vie, le droit chemin à suivre, quand l'honneur ne s'accorde pas avec l'intérêt, les exigences des affaires publiques et privées, la modération dans la gloire et son dernier degré, l'amour qu'on doit à sa patrie, et enfin la piété filiale». En mars i 550 , L'Hospital fait l'éloge de Cicéron à Marguerite, c'est lui qui enseigne de vitae officium, le droit chemin à suivre quand l'honneur et l'intérêt ne s'accordent pas, les exigences des affaires publiques et privées, la modération dans la gloire et l'amour pour la patrie, l'amitié et enfin la piété filiale. Cf. aussi l'Epître Ad Pontronium, 26-28/i 585 : 34-35, où l'on trouve la liste des auteurs aimés par la jeune princesse: Virgile, Horace, Cicéron, princes de la langue latine. Michel se demande toutefois: «les- 
a-t-elle quittés dans ces temps sacrés pour se pénétrer des livres saints?» ce qui semble indiquer un revirement, après I 550, une "conversion" à la littérature sacrée. Nous conservons l'exemplaire d'Horace (Poemata, Paris, Vascosan, I 545) de Marguerite relié avec son initiale M en semé (Turin, BN, Ris. I6/I9), cf. Gorris Camos, La Bibliothèque de la duchesse cit. C'est probablement le même qu'elle fit acheter avec des Commentaires en I 550.

Io6. Cf. le dialogue $A d$ amicos, p. 344.

107. Sur Mile Perot, cf. R. Gorris Camos, Dans le labyrinthe de Jacques Gohory, traducteur de Machiavel, in «Laboratoire italien», n. 8, Géographie et politique au début de l'âge moderne, sous la direction de Paolo Carta et de Romain Descendre, Lyon, ENS, 2008, pp. 195-229.

I08. Sur l'intérêt de Perot et de Gohory pour les théories de Machiavel, Gorris Camos, Dans le labyrinthe cit., pp. 195-229.

I 09. Crouzet a mis en évidence l'antimachiavélisme de Michel de l'Hospital, D. Crouzet, La sagesse et le malheur. Michel de l'Hospital cit, p. 323. Pour lui les Carmina sont «au tournant de la décennie i 560 et surtout dans le moment historique de leur publication posthume, le corpus d'invention précoce ou de cristallisation première de l'antimachiavélisme français $\mathrm{du} \mathrm{XVI}^{\mathrm{e}}$ siècle».

i ı. Cf. le dialogue $A d$ amicos, p. 345.

i i I. Cf. C. Ossola, Introdurione, in VALDES, Le Evangelio cit., p. 52 qui parle de Le Fèvre comme d'un «diffusore della formula del beneficio». Il ajoute, p. 74: «la parabola di Jacques Le Fèvre parrà in Italia, straordinariamente simile a quella del Valdès». Voir les Epistres et Evangiles, éd. M. A. Screech, Genève, Droz, I 964.

I I 2. Epistres et evangiles, éd. cit., 24 b, 23 a, 40 a, 52 b, I 3 b, 46. Cf. Ossola, Introdurione, in VALDES, Le Evangelio cit., p. 68 sq. qui cite les censures de la Sorbonne à ces passages.

I I 3. Exemplaire conservé à la B.N. de Turin (cote: Ris. I9. I 2-1 5). Cf. W. J. Van Eys, Bibliographie des Bibles et des Nouveaux Testaments en langue française des XV et $X V T^{R}$ siècles, Genève, H. Kündig, I 900-1901, I, 30 et B. Thomas Chambers, Bibliography of French Bibles, Fifteenth-and Sixteenth-Century French-Language Editions of the Scriptures, Genève, Droz, I983, p. 60 sq.

I 14. Cf. l'édition du Miroir par Lucia Fontanella, Alessandria, Dall'Orso, i984, p. 370 .

I I 5. Original autographe BnF, Dupuy 90I, ff. 59r-6or. Claude d'Espence fera traduire ces poèmes par Anne de Marquets, Les divines Poesies de Marc Antoine Flaminius, Paris, Chesneau, i 568. Cf. E. Balmas, Anne de Marquets, Claude d'Espence e la fortuna del Flaminio in Francia, in «Bollettino della Società di studi valdesi», I 9 (1966), pp. 24-42 et réuni in Saggi e studi sul Rinascimento francese, Padoue, Liviana, 1982, pp. I 35-62; G. Ferguson, Le chapelet et la plume, ou, quand la religieuse se fait écrivain: le cas du prieuré de Poissy (I562-I62I), in «Nouvelle Revue du Seizième 
Siècle», 200 I, I9/2, pp. 83-99; Anne De Marquets, Sonets spirituels, éd. G. Ferguson, Genève, Droz, I 997; G. Ferguson, «Une nonain latinisante» Anne de Marquets, in Poésie et Bible de la Renaissance à l'âge classique, Actes du colloque de Besançon, 25 et 26 mars 1996, Paris, Champion, I999, pp. i 83-97.

i 6. «En mourant, il n’a plus songé aux choses de la terre, mais il a accordé sa lyre pour faire monter jusqu'aux cieux ses saintes poésies et te léguer un dernier souvenir: royal présent offert à une royale princesse», cf. Sur les vers sacrés de Flaminus, poète florentin, pp. 74-75.

I 17. Une autre édition sera publiée en I 554, M. Antonii Flaminii De rebus divinis carmina, Tiguri, Ex Officina Froschoviana, I 594 (un ex. B.N. de Florence, Fonds Guicciardini 2.I-4.2-34).

i 1 8. Cf. L. Petris, La plume et la tribune. Michel de L'Hosptial et ses discours (I559-I562), Genève, Droz, 2002, p. I64.

I i 9. Cf. L. Petris, Le théologien et le magistrat: Claude d' Espense et Michel de l'Hospital, in Un autre catholicisme au temps des réformes? Claude d'Espence et la théologie humaniste à Paris au XVT siècle, Etudes originales, publications d'inédtis, catalogue de ses éditions anciennes, éd. par Alain Tallon, Turnhout, Brepols, "Nugæ I 2", 2010, p. I99.

I 20. Petris, Le théologien et le magistrat cit., p. I94. D’Espence dédie à Michel un commentaire inédit sur la $2^{\mathrm{e}}$ épitre aux Corinthiens, Fonds Camerarius de Munich, (Clau. Despensius Theol. Michaeli Hospitalio Senatori Parisiensi, Quasi morientes, et ecce, vivimus. 2. Corinth. 6, Munich, Bayerische Staatsbibliothek, Camerarius, CLM 10383, ff. 364r-365v, cf. Petris, Le théologien et le magistrat cit., p. 205 , n. 59).

I 2 I. Petris, Le théologien et le magistrat cit.

i 22. D. Martin Luthers, Werke, pp. I04-34. Rédigé en i 5 I9, le texte connait au moins cinq éditions latines en deux ans.

I 23. Consolation en ad-/VERSITÉ./Faite par M. Claude d'Espence/docteur en Theologie./A LYON,/PAR IEAN DE TOURNES./M.D.XLVII..// I6 $6^{\circ}$ : A-I. Car. Romains; ex. BnF, D 88506 (3) et Genève, BGE, Rés. Bd I 888. Le texte a été republié à Paris en I 548, dans Paraphrase, ou meditation, sur l'oraison Dominicale. Et autres Opuscules, comme trouverez en la page suyvante. Le tout composé par M. Claude Despence, Docteur en Theologie de Paris, à Paris, en l'imprimerie de René Avril, I 548 et, toujours en I 548, par Groulleau. Cf. pour une description bibliographique des différentes éditions: A. Dubois, Bibliographie des éditions de Claude d'Espence, in Un autre catholicisme au temps des Réformes? cit., p. 345, I 547/I; p. 350, I 548/4 et p. 352 , I 548/5. Sur les étranges parcours de ce texte, voir F. Higman, Lire et déconvir la circulation des idées au temps de la Réforme, Genève, Droz, I998, pp. 223-24 et les Index de l'Université de Paris de: I 544, I 545, I 547, I 549, I 55 I, I 556, J. Martínez de Bujanda, F. M. Higman, J. K. Farge édd., Genève, Droz, I 985 . Sur la Consolation, voir aussi l'étude de Petris, Le théologien et le magistrat cit., pp. I93-2 I I. En i 566, le théologien offre un ouvrage religieux à Marguerite de Valois: Collectarum ecclesiasticarum liber vnus ad D. Margaritam christianiss. regis sororem per Claudium Espencaeum 
Parisiensem theologum. Quae accesserunt, Parisiis, apud viduam Guil. Morelij typographi regij, I 566.

I 24. Cf. Petris, Le théologien et le magistrat cit., p. 205.

i 25. Cf. Garnier-Mathez, L'épithète de la connivence cit., pp. 288-30s et Petris, Le théologien et le magistrat cit., p. 209.

I 26. Luther, dans la préface de son édition de I 535 , cite Romains I 5,4 pour dire que l'Ecriture est source de consolation.

I 27. Pour une analyse détaillée de la Consolation, cf. R. Gorris Camos, Le lys et la croix: constellations familiales dans la bibliothèque de Marguerite de France, duchesse de Savoie in La verve, laplume et l'échoppe. Études renaissantes à la mémoire de Michel Simonin, C. Lastraioli, R. Uetani, M.-L. Demonet édd., Turnhout, Brepols, 2012 (sous presse).

I 28. Colonna, Rime, éd. Bullock, p. 3.

I 29. Cf. s. ıo6, 8 «Me consolant d'excuse, ou de pitié»; s. Io8, 7 «Console donq' cet esprit ennuyé».

I 30. Cf. s. i65, Colonna, Rime, éd. Bullock, p. i67.

i 3 i. Cf. Marcantonio Flaminio, Lettere, éd. A. Pastore, Rome, Edizioni dell'Ateneo \& Bizzarri, I 978, p. 75 sq. Voir aussi l'édition de ses écrits inédits: Marcantonio Flaminio, Apologia del Beneficio di Cristo e altri scritti inediti, D. Marcatto éd., Florence, Olschki, I 997 qui contient ses Lettere sulla giustificazione: Della giustificazione et Della medesima giustificazione. Sur le rôle de Flaminio dans la Réforme italienne, voir M. Firpo, Il Beneficio di Christo e il Concilio di Trento (I542-I546), in «Rivista di storia e letteratura religiosa», XXXI (1995), I, pp. 45-72 et surtout A. Pastore, Marcantonio Flaminio. Fortune e sfortune di un cherico nell'Italia del soo, Milano, Angeli, I 98 I.

I 32. Lors de son séjour parisien (I 547-I 5 3), Pietro Carnesecchi fréquenta l'hétérodoxe espagnol Juan Morillo, collaborateur de Pole à Trento. Dans la sentence de son procès on lit: «ivi [à Paris] praticasti con alcuni heretici et altri personaggi sospetti d'heresia, et tanto in Lione nell'andare et tornare quanto in Parigi et in quella corte leggesti li Luochi del Melantone et altri libri sospetti, et facesti venire dall'Italia un libro asperso d'heresia del Valdès e lo donasti, non ti rimovendo dalle dette false et heretiche opinioni», voir M. Firpo, D. Marcatto, Il processo inquisitoriale di Pietro Carnesecchi (I557-I576), Edizione critica, II. Il processo sotto Pio V (I 566- I 567), Città del Vaticano, Archivio Segreto Vaticano, 2000. Sur son séjour parisien, cf. Firpo, Pietro Carnesecchi, Caterina de' Medici e Juan Valdès cit., pp. 75-88. Sur son rôle pour l'édition des Des rebus divinis carmina, cf. O. Ortolani, Pietro Carnesecchi, Florence, Le Monnier, I963, pp. 74-75. Sur son amitié pour Flaminio, cf. Pastore, Marcantonio Flaminio. Fortune e sfortune cit., p. I I 3 et Firpo, Marcatto, Il processo inquisitoriale di Pietro Carnesecchi cit., I, p. 63, p. 244 et passim, leurs noms sont en effet constamment associés dans ces documents.

I33. Cf. sur la conception de la justification par la foi, Il processo inquisitoriale di Pietro Carnesecchi cit., I, p. 377 sq. où il affirme devoir à Giulia Gonzaga le fait de 
s'être délivré de «la superstitiosa e falsa religione, intendendo per tale quella che era diversa dalla fede et dottrina insegnata a lei et a me da Valdès. In quanto quella poneva la speranza della sua salute nelle opere, dove questa la pone nella fede».

i 34. Cf. Marcantonio Flaminio, Apologia del Beneficio di Cristo e altri scritti inediti cit.

I 35. Sur Giulia Gonzaga, fidèle disciple de Valdès: G. Dall'Olio, Gonzaga, Giulia, in Dizionario Biografico degli Italiani, LVII, Rome, Istituto dell'Enciclopedia Italiana, $200 \mathrm{I}$, pp. 783-87; B. Amante, Giulia Gonzaga contessa di Fondi e il movimento religioso femminile nel secolo XVI, Bologne, Zanichelli, I 896; L. Muccitelli, La contessa di Fondi Giulia Gonzaga (Gazzuolo Mantovano IsI3 - Napoli I566), Fondi, Lo Spazio, 2002; A. Di Fazio, Giulia Gonzaga e il movimento di riforma, Marina di Minturno, Caramanica, 2003; M. Firpo, Tra alumbrados e "spirituali". Studi su Juan de Valdès e il valdesianesimo nella crisi religiosa del soo italiano, Florence, Olschki, I990 et les travaux récents de Susanna Peyronel qui est en train de publier sa correspondance, voir par exemple S. Peyronel, I carteggi di Giulia Gonzaga in Donne di potere nel Rinascimento, Actes du Colloque de Milan, les 29 novembre-2 décembre 2006, Rome, Viella 2008, pp. 709-742 et C. Russell Giulia Gonzaga and the Religious Controversies of Sixteenth Century Italy, Turnhout, Brepols, 2006.

I 36. Cf. Il processo inquisitoriale di Pietro Carnesecchi cit., I, p. 30I. Et il ajoute (II, p. 4I 5) un magnifique portrait de sa protectrice: «Quanto poi a quello che io dico di madama Margarita, cioè che la fusse una donna per natura reale et per regeneratione divina, volevo intendere ch'[e]lla haveva quella generosità et grandezza d'animo che conveniva a una che fusse nata di sangue reale come lei et d'altra parte era dotata di quella charità, humiltà et mansuetudine che si rechiedeva a una excellente christiana et che fusse regenerata per lo spirito di Dio, cioè che havesse racquistato mediante la gratia de medesimo Dio quella divina imagine secondo la quale siamo simili a Dio».

I 37. E. Jodelle, A Tres Illustre Princesse Marguerite de France, Estienne Jodelle Parisien in Oeuvres complètes, éd. E. Balmas, Paris, Gallimard, I965, I, pp. 99-1 02 . Voir aussi les très importants sonnets A Madame Marguerite, saur du Roy Henry deuxiesme, depuis Duchesse de Savoye, in Oeuvres complètes, I, pp. I63-65 qui révèlent l'attitude religieuse de Marguerite, cf. le commentaire d'Enea Balmas, pp. 465-66 qui écrit: «parler de Dieu, dans un salon parisien de I 557 , évoquer la nécessité de l'engagement qu'il réclame de nous ("Doit estre aux biens, aux maux, le seul but du Chrestien”, II, v. 4), mettre énergiquement l'accent sur le nom du Christ, vrai fondement de la foi et unique espoir des chrétiens divisés [...] signifie adopter, involontairement peut-être, mais inévitablement, une attitude cripto-réformée». Dans ses Christianorum nostri temporis heroum, et heroinarum icones, recueil dédié à Marguerite, le poète évoque dans Eiusdem Palladium semper inter meos lares habitum (I, I93) son Palladium, une statuette représentant sa protectrice sous les traits de Pallas qui représentait pour le poète une sorte de talisman.

I 38. Cf. Campi, Michelangelo e Vittoria Colonna cit., p. 45 qui écrit: «non si vede con quali argomenti si potrebbe contestare il carattere imputativo, estrinseco che in questi versi la giustificazione chiaramente riveste». Le critique cite les sonnets 59 et I 2 des Rime, cf. éd. Bullock, p. i 44 et p. I 83. 
I39. Colonna, Rime, éd. Bullock, p. i63.

I40. Cf. Campi, Michelangelo e Vittoria Colonna cit., p. 47.

I4I. Cf. Campi, Michelangelo e Vittoria Colonna cit., p. 48.

I42. Firpo, Tra alumbrados e "spirituali" cit., p. 2 I 8.

i43. Colonna, Rime, éd. Bullock, p. 9 I.

i 44. Colonna, Rime. Cf. Firpo, Tra alumbrados e "spirituali" cit., p. 220-2 I et Ossola, Introduzione cit., p. 83.

I45. Cf. le Relevé complet après lemmatisation dans le CD réalisé par Ėryc Lysøe, à l'occasion du Colloque de Lucelle qui signale i 2 récurrences. Cf. aussi pour le mot «foy», Buron, Du sonnet CXIV à la dédicace cit., p. I 36 . Sur les connotations évangéliques du recueil voir: Garnier-Mathez, L'épithète de la connivence cit.; Ead., Entre pétrarquisme et néo-platonisme: réminescences évangéliques dans L'Olive, in Du Bellay. La Deffence \& L'Olive. Lectures croisés cit., pp. 107-26 et Gorris Camos, Sous le signe de Pallas cit., passim.

i46. Colonna, Rime, éd. Bullock, p. 25.

I47. Cf. Bolzoni, Il cuore di cristallo cit.

I 48. Pour les récurrences des mot «clair» (I 5), «clarté» (I I), «lumière» (6) et pour le lexique du feu, de la lumière et de l'obscurité «obscur» (7), «noir» en général (25), cf. le Relevé complet après lemmatisation dans le CD réalisé par œryc Lysøe, à l'occasion du Colloque de Lucelle.

149. I processi inquisitoriali di P. Carnesecchi cit., p. 270.

I 50. Cf. notre Sul II2 dell'Olive cit., passim.

I 5 I. Cf. la «Liste des incipit de sonnets pétrarquiens imités dans L'Olive», in Millet, Du Bellay et Pétrarque cit., pp. 264-66.

I 5 2. Voir la belle étude de A. Bettoni, Il sonetto di Veronica Gambara sulla predestinaz̧ione in Du Bellay, in «Italique», VI (2002), p. 48 qui relève dans l'indice du Libro Secondo, la position en explicit de ce sonnet, indiqué sous le prénom Veronica (Delle Rime di diversi nobili huomini et eccellenti poeti nella lingua thoscana. Nuovamente ristampato, Libro secondo, Venezia, Giolito, I 548, f. 39v). Anna Bettoni signale aussi un sonnet Nel lor principio eterno fisse e intente de F. Figliucci, traducteur de Ficin, qui a la même rime et des affinités thématiques remarquables, cf. Delle rime di diversi nobili buomini et eccellenti poeti, I 548 , f. I I $5 \mathrm{v}$.

I 53. Sur les rapports intertextuels entre l'Olive et l'Orlando Furioso, voir les éditions citées d' E. Caldarini; d'O. Millet; de H. Chamard, Cuvres poétiques, I, I908, nouvelle éd. mise à jour et complétée par Y. Bellenger, Paris, Nizet, I989; de D. Aris et Fr. Joukovsky, CEurres poétiques, I, Premiers recueils (I 549-I 55 3), Paris, Garnier, I993, ainsi que les études de Gorni, I tempi dell'Olive cit.; de J. Vianey, 
L'Arioste et la Pléaide, in «Bulletin italien», n. I-23 (1901), pp. 295-317 et Id., Le Pétrarquisme en France au XVI siècle, Montpellier-Paris, Coulet, I 909 en part. p. 85 sq.; de K. W. Hempfer, Traditions discursives cit.; de A. Cioranescu, L'Arioste en France. Des origines à la fin du XVIII siècle, Paris, Presses Modernes, I939, I, 202-67; A. Cameron, The Influence of Ariosto's Epic and lyric Poetry on Ronsard and His Group, Baltimore, Johns Hopkins, I930; R. Schwaderer, Das Verbältnis des Lyrikers Joachim Du Bellay zu seinen Volbildern. Probleme der «imitatio», Würzburg, E. Schmitt \& und M. Mayer i 968 , pp. 40-173.

I 54. Sur Correggio, cf. G. Fragnito, Girolamo da Correggio, DBI, tome 29, ad vocem et AA. VV., Veronica Gambara e la poesia del suo tempo nell'Italia settentrionale cit., et notamment A. Ghidini, La contea di Correggio ai tempi di Veronica Gambara, pp. 79-98. Cf. aussi Gambara, Le Rime, éd. Bullock cit.

I 5 5. Sur le rôle de Marguerite, protectrice des réformés bannis de France, C. H. Patry, Le protestantisme de Marguerite de Savoie, in «Bulletin de la Société de l'Histoire du Protestantisme», LIII (1 904), pp. 7-26; T. Heyer, Marguerite de France, duchesse de Savoie, ses rapports avec Genève (I563-1567), in «Mémoires et documents publiés par la Société d'histoire et d'archéologie de Genève», XV (1865), pp. i 22-44. Voir la lettre de Calvin à Renée, du 4 avril i 564 , où il écrit: «J'ay entendu que Madame la duchesse de Savoie, vostre niepce est en assez bon train, jusques à estre déliberée de se declairer franchement». Cf. Heyer, Marguerite de France cit., p. I 26 et maintenant R. Gorris Camos, L'ange de Loth: Calvin et la duchesse, in Giovanni Calvino nel quinto centenario della nascita. Interpretazioni plurali tra dissenso evangelico e critica cattolica, Actes du Colloque Florence, les I4-16 mars 2009 Paris, Garnier, (sous presse) et Ead., «Pia ricevitrice di ogni cristiano»: poésie, exil et religion autour de Marguerite de France, duchesse de Savoie, in Chemins de l'exil, havres de paix. Migrations d'homme et d'idées au $X V I^{e}$ siècle, C. Lastraioli et J. Balsamo édd., Paris, Champion, «Le Savoir de Mantice», 2010, pp. 177-223.

156. Libro primo delle Rime, Venise, Giolito, i 545. Sur ces anthologies, cf. A. Nuovo, C. Coppens, I Libri di rime: serialità e concorrenza cit., p. I I sq.; Tomasi, Alcuni aspetti delle antologie liriche del secondo Cinquecento cit., pp. 77- I I I.

I 57. Sur Giuseppe Betussi, qui a travaillé longtemps à Venise chez Giolito voir L. Nadin Bassani, Il poligrafo veneto Giuseppe Betussi, Padova, Antenore, $199^{2}$ et A. Nuovo, C. Coppens, I Libri di rime: serialità e concorrenza cit., pp. 93 n., Ios, i Io, I I 9-20, I 22 n., I 32, 396 n. Sur Lodovico Domenichi, voir A. D’Alessandro, Prime ricerche su L. Domenichi, in Le corti farnesiane di Parma e Piacenza (I545-1622), A. Quondam éd., I 978, pp. I71-200 et surtout E. Garavelli, Lodovico Domenichi e i "Nicodemiana" di Calvino. Storia di un libro perduto e ritrovato, avec une présentation de Jean-François Gilmont, Manziana, Vecchiarelli, 2004 qui publie sa traduction des Nicodemiana de Calvin et la riche bibliographie, toujours établie par E. Garavelli, publiée sur le site de Cinquecento plurale in wnw.nuovorinascimento.org.

I 58. "[Margherita] ha dimostrato quanto larga, e ampia sia la strada di seguitar Christo, che a molti pare angusta, et intricata. Imperoché col rinchiudersi, non solamente ne i muri, e nei monasteri, ma vivendo anche mondanamente nello stato che l'huomo con moglie et la donna con marito, e l'uno e l'altro senza, si trova, e si può seguir i precetti di Dio, e oprar bene, senza sotto fintione di 
religione, e santimonia ingannare il vulgo, non già Iddio, ma bene se stessi. Questi secondo occasioni sono di que veri mezzi, per li quali si diventa illustri appo il mondo, e chiarissimi in cielo, non bastando solamente l'essere uscite di nobil sangue, quanto anco si conviene operar cose degne del grado»; ce beau portait est publié in LIBRO DI M. GIO./BOCCACCIO DELLE DON-/NE Illustri, Tradotto per Messer/ Giuseppe Betussi./CON UNA ADDITIONE FATTA/del medesimo delle donne Famose del Tempo di/M. Giovanni fino a $\mathrm{i}$ giorni nostri e, alcune altre state per inanzi,/CON LA VITA DEL BOCCACCIO,/e la Tavola di tutte l'historie, et cose principali, che nell'opra si contengono./ALL'ILLUSTRISS. S. CAMILLA/Pallavicina Marchesa di Corte Maggiore./IN VENETIA MDXLVII.// Con la vita del Boccaccio, In Venetia, per Pietro Nicolini da Sabbio, I 547.

i 59. Cf. G. Briçonnet, M. De Navarre, Correspondance, éd. Christine Martineau et Michel Veissière, Genève, Droz, I975, I, 25. Voir aussi le beau livre de: R. D. Cottrell, La Grammaire du silence. Une lecture de la poésie de Marguerite de Navarre, Paris, Champion, I995, p. 9 sq.

i6o. Carteggio di Vittoria Colonna, éd. E. Ferrero et G. Muller, Turin, i 889, p. ig6 et la lettre de Vergerio in Lettere volgari di diversi nobilissimi huomini, Vinegia, I 542, f. 102 .

i6ı. Voir sur les rapports entre Marguerite de Navarre et les milieux réformés italiens: R. Cooper, Marguerite de Navarre et la Réforme Italienne, in Marguerite de Navarre 1492-1992, Actes du Colloque international de Pau (1992), réunis par N. Cazauran et J. Dauphiné, Mont-de-Marsan, Éd. Interuniversitaires, I995, p. I 59-88 et R. Gorris Camos, Le fleuve et le pré: rhétorique du ccour et de l'esprit dans l'Heptaméron de Marguerite de Navarre, in Pratiques de la rhétorique dans la littérature de la fin du Moyen Age et de la première modernité, Actes du Colloque de Wolfenbüttel, 9-II octobre 2003, Herzog August Bibliothek, Turnhout, Brepols, 2006, pp. $65-88$.

I62. Gorni, I tempi dell'Olive cit., p. 58.

163. Cf. G. Fragnito, Intorno alla religione dell'Ariosto: $i$ dubbi del Bembo e le credenze ereticali del fratello Galasso, in «Lettere italiane», 44 (1992), pp. 208-32 et A. Prosperi, L'eresia del Libro Grande. Storia di Giorgio Siculo e della sua setta, Milan, Feltrinelli, 2000.

I64. Cf. le catalogue de l'exposition Une Renaissance singulière. La cour des Este à Ferrare, Bruxelles, Editions Snoeck - Silvana Editoriale, 2003.

i65. Voir sur le Beneficio di Cristo: Benedetto da Mantova, Il Beneficio di Cristo. Con le versioni del secolo XVI, documenti e testimonianze, S. Caponetto éd., FlorenceChicago, Sansoni-The Newberry Library, I972; Firpo, Il Beneficio di Christo $e$ il Concilio di Trento (I542-1546) cit., pp. 45-72; Flaminio, Apologia del Beneficio di Cristo e altri scritti inediti cit.; T. Bozza, Nuovi studi sulla Riforma in Italia. I. Il Beneficio di Cristo, Roma, Storia e letteratura, 1976; C. Ginzburg, A. Prosperi, Giochi di pazienża. Un seminario sul "Beneficio di Cristo", Turin, Einaudi, 1975; P. Simoncelli, Nuove ipotesi e studi sul "Beneficio di Cristo", in "Critica storica», XII (I975), 
pp. 320-88; Id., Evangelismo italiano del Cinquecento. Questione religiosa e nicodemismo politico, Rome, Istituto italiano per l'età moderna e contemporanea, I979; M. Rosa, In margine al Trattato del Beneficio di Cristo, in "Quaderni storici», 22 (1973), pp. 28 5-88 et Il Beneficio di Cristo: interpretazioni a confronto, in «Bibliothèque d'Humanisme et Renaissance», XL (1978), pp. 609-20.

I66. Pour les condamnations du Beneficio, interdit par l'Index parisien de I 547 (il s'agit de la traduction lyonnaise de I 545 de Claude Lemaistre, l'un des amis de Marot, cf. M. Simonin, De Marot à Ronsard: Les Traductions de Latin en François (I550-I555), in Clément Marot "Prince des poëtes françois" I496-1996, Paris, Champion, I 997, pp. 759-82), par l'Index de Venise en I 549, par celui de Paul IV, en I 559, et par celui de Pie IV, en I 564, voir: Index des livres interdits, J. Martinez de Bujanda éd., Sherbrooke - Genève, Centre d'Études de la Renaissance de l'Université de Sherbooke-Droz, 1984 sq., I, pp. 325-26; III, pp. 197-98, 229, 39I, 398; VIII, pp. $385,694,757,870$.

I67. Seidel Menchi, Le traduzioni italiane di Lutero cit., p. 87. Voir maintenant sur la traduction du Benefice: G. Berthon, Quelques nouveautés bibliographiques autour d'Étienne Dolet et Jean de Tournes: Les Psaumes de Marot et le Benefice de Jesuschrist de Benedetto da Mantova traduit par Claude Le Maistre (I544-I545), "BSHPF", sous presse.

I68. Cf. AA. VV., Veronica Gambara e la poesia del suo tempo cit., p. 90 et p. 94.

I69. Cf. la note I67 ci-dessus et notamment les études de Firpo et de Marcatto sur le rôle fondamental joué par M. Flaminio pour la rédaction du libretto, cf. Firpo, Il Beneficio di Christo cit., pp. 52, 53,63 et l'Introduzione de D. Marcatto à Flaminio, Apologia cit., p. 7 sq.

I 70. Firpo, Marcatto, Il processo inquisitoriale del cardinal Giovanni Morone cit., pp. 363 , 462; I, 228. Cf. Firpo, Il Beneficio di Christo cit., p. 50 et Flaminio, Apologia cit., p. 200 sq.

i 7 I. Sur Marcantonio Flaminio, voir Pastore, Marcantonio Flaminio cit.; Flaminio, Lettere cit.; FLlaminio, Apologia cit. et Marcantonio Flaminio nel $V$ centenario della nascita (Serravalle I498-Roma I550), A. Pastore et A. Toffoli édd., Vittorio Veneto, Comunità montana delle Prealpi trevigiane, 200I. Sur les rapports entre Flaminio et la France, voir: E. Balmas, Anne de Marquets, Claude d'Espence e la fortuna del Flaminio in Francia cit.; Augé-Chiquet, Jean-Antoine de Baïf et Marc Antonio Flaminio, in Mélanges littéraires, Clermont-Ferrand, I910, pp. 193-99; F. A. Yates, French Academies of the Sixteenth Century, Londres, 1947, p. 7I et p. 205. Scévole de Sainte-Marthe imite aussi Flaminio, voir son Chant de la Santé pris du latin de M. A. Flamin, in Premieres CEuvres, Paris, F. Morel, i 569 , f. I 2. Sur cette influence, cf. A. J. Farmer, Les cuures françaises de Scévole de Sainte-Marthe, Toulouse, Privat, I920, pp. 37-40, 66, 94, I I 3, I 20.

172. Cf. M. Firpo, Riforma protestante ed eresie nell'Italia del Cinquecento, Bari, Laterza, 1993, p. I09.

173. Flaminio, Lettere cit., p. 63; Firpo, Riforma protestante cit., p. i i i, n. 26. Cf. aussi l' Apologia, éd. cit., p. 83 sq. Sur la dispute théologique concernant le 
libre arbitre, cf. A. Pastore, Nel tempestoso mare dell'eretica confusione, in Marcantonio Flaminio cit., p. 90 sq. et notamment pp. 97-107.

174. Processo Carnesecchi cit., pp. 552-53. On lit aussi dans les Actes: «Ch'el Flaminio legeva san Matteo al Carnesecco, Soranzo, Prioli, etc., parlando della giustificatione per el sangue de Christo e non per le nostre opere, le quali opere però sono necessarie et che necessariamente procedono dalla fede, come li frutti buoni dal buon arbore et come il calor dal fuocho, e che chiunque sente in sé [vivamente questa giustificazione] per Christo può star securo della sua salute. Et [in] alio loco: Il Flaminio et Carnesecca me dicevano che N. [la duchessa di Ferrara] et N. [quella di Camerino] intedevano la giustificatione come di sopra», I, p. 490 e aussi p. 5 I 3.

175. Introduzione de Marcatto à Flaminio, Apologia cit., p. 7 sq. Sur Giulia Gonzaga voir supra n. I36.

i76. Flaminio, Apologia cit., p. 72.

I77. Sur la condamnation des œuvres de Flaminio, cf. L'Index des livres interdits, éd. J. Martinez de Bujanda cit.,VII, pp. 292-96. Cf. aussi le «Terzo costituto di Pietro Carnesecchi», Rome, is mai I 60 , in Firpo, Marcatto, I processi inquisitoriali di Pietro Carnesecchi cit., I, p. 59 où l'ami de Flaminio déclare avoir lu des livres «prohibiti da Papa Paulo IIII, como saria le Adnotatione di Erasmo sopra il Testamento novo et Psalmi di Marcantonio Flaminion, et p. 174, p. 25 I, p. 288, p. 3 Io, p. 423 et p. 476 .

178. Les ouvrages de Flaminio sur les Psaumes furent publiés à plusieurs reprises en Europe. En I 540, Flaminio publie à Venise: In librum Psalmorum brevis explanatio ad Alexandrum Farnesium Cardinalem amplissimum, Venetiis, Aldus, MDXLV, qui sera réédité à Venise en i $545(\mathrm{BnF}, A 675$ I et Rés. $A$ 675 Ibis); Paris, Ruelle, I 546 ; à Lyon, Rovillium, I 548 (ex. BnF, $A$ 6753); à Paris, Parvum, I 549 (BnF, $A$ 6754); à Lyon, Rovillium, en I 552 et I 553 (Bnf, $A 6755$ et $A 6756$ (I); à Venise avec la Paraphrasis, en I 564, chez Paolo Manuzio. En I 546, toujours à Venise, mais chez Vincenzo Valgrisi, il publie sa Paraphrasis in triginta Psalmos versibus scripta ad Alexandrum Farnesium Cardinalem amplissimum, Venetiis ex officina Erasmiana apud Vincentium Valgrisium, MDXLV (ex. BnF, A 6848 I) qui sera reprise, avec un immense succès, à Paris en I 546 , chez R. Estienne, à Florence, en I 548 et en I 552 chez Torrentino; à Paris, chez Petit, I 549 (ex. Turin, Fondation Firpo). En I 548 , Gryphe publie à Lyon ses Carminum libri duo, suivi par la Paraphrasis (ex. Arsenal, $8^{\circ} B$ 5602). Ces œuvres marquent son retour à la réflexion sur les psaumes déjà entamée lors des années véronaises dans sa Paraphrasis in duo et triginta psalmos, Venetiis, in officina Joanni Patavini, I 538.

I79. Cfr. JacQues Grevin, «Puisse l'immortelle Olive / T’ombrager à tout jamais, / Afin que ton nom revive», in A Robert Estienne, Ode, vv. 82-84, Gélodacrye, éd. M. Clément, Saint-Étienne Publications de l'Université de Saint Etienne, 200 I p. I 3 et En faveur de l'Olive, p. I I 4 .

i 8o. M. ANTONII FLAMINII PA-/raphrasis in triginta Psalmos versibus scripta./Ad Alexandrum Farnesium Cardinalem amplissi-/mum [marque des 
Estienne]/LUTETIAE,/Ex officina Roberti Stephani typographi Regii/ MDXLVI//. Nous avons consulté l'ex. BnF Rés. A 6848 appartenu à Michel de Montaigne (Michaelis montanus I549) et qui présente un ex-libris de Daniel Huet. La même année Estienne publie La Coltivatione de Alamanni, autre poète de Marguerite. Cf. sur l'édition de Flaminio, E. Armstrong, Robert Estienne, Royal Printer: an Historical Study of the Elder Stephanus, Abingdon, Sutton Courtenay press, I 986, p. 29. Une autre édition fut publiée, en I 556, par Henri Estienne: Davidis Psalmi aliquot, Latino Carmine expressi a quatuor illustribus poetis: quos quatuor regiones, Gallia, Italia, Germania, Scotia, genuerunt S. Macrino, M. A. Flaminio, Eobano, G. Buchanan, Scotia, et Iovita Rapirio, ex. officina H. Stephani, I 556, in $4^{\circ}$ (Bnf, A 3 I 40), cf. La France des bumanistes, Henri II Estienne éditeur et écrivain, J. Céard dir., Turnhout, Brepols, 2003, p. I4.

I8 I. M. H. Seiler, Anne de Marquets poétesse religieuse du XVI siècle, Thèse de l'Université Catholique d'Amérique, Washington i93 I, p. 56 et Balmas, Sulla fortuna del Flaminio cit., p. I40.

I 82. Dans l'édition Plantin, la dédicace AD MARGARITAM HENRICI Gallorum Regis Sororem est remplacée par un autre poème $A D$ CHRISTUM.

I 83. Salmonij Macrini/IULIODUNENSIS/Cubicularij Regij Epitome vitae Do-/mini nostri IESU CHRISTI,/Ad MARGARITAM VALESIAM, Henrici Fran-/corum Regis sororum unica./ Varia item poëmatia, et de sacra Regis unctione, et de/ejusdem triumphali in urbem Lutetiae introitu./ PARISIIS,/Ex typographia Matthaei Davidis, via amygdalina,/quae est è regione collegiij Rhemensis/Ad Veritatis insigne./I 549./ (ex. BnF, Yc 8325 et Richelieu, Arts du spectacle $\left.8 R a^{\circ} 7 I\right)$. Cf. Heyer, Marguerite de France cit., p. I 8.

I 84. Firpo, Marcatto, I processi inquisitoriali di Pietro Carnesecchi cit., I, p. I42.

I 8 5. Voir Beneficio di Cristo. Con le versioni del secolo XVI, Documenti e testimonianza, a cura di S. Caponetto, Firenze-Chicago, 1972 et n. i I 5 ci-dessus et Pastore, Marcantonio Flaminio cit., p. I 22 sq.

I 86. Balmas, Sulla fortuna del Flaminio cit., p. I49.

I 87. Sur le rapport de profonde dévotion de Du Bellay pour Marguerite voir la Lettre du mesme autheur à un sien amy sur la mort du feu Roy et le departement de madame de Savoye, un départ qu'il considère un «desastre» et qui l'a «tellement estonné et fait perdre le cœur, que je suis deliberé de jamais plus ne retenter la fortune de la court, m'ayant, nescio quo fato, esté jusques icy tousjours si marastre et cruelle». Elle était pour lui «l'unique support et refuge de la vertu, et de ceux qui en font profession» (CEuvres Poétiques, VI, Discours et Traditions, éd. H. Chamard, Paris, Droz, pp. 99-100). 